\title{
NICKEL ISOTOPE FRACTIONATION AS A FUNCTION OF CARBONATE GROWTH RATES DURING NI COPRECIPITATION WITH CALCITE
}

\section{Cristina Castillo Alvarez ${ }^{a}$, Ghylaine Quitté ${ }^{b}$, Jacques Schott ${ }^{a}$ and Eric H. Oelkers $^{\text {a }}$ \\ ${ }^{\mathrm{a}}$ GET, CNRS-Université de Toulouse, UMR 5563, 31400 Toulouse, France, ${ }^{\mathrm{b}} 7$ IRAP, Université de Toulouse, CNRS, UPS, CNES, UMR 5277, 31400 Toulouse, France,}

\section{Abstract}

The fractionation of $\mathrm{Ni}$ isotopes during $\mathrm{Ni}$ coprecipitation with calcite was measured at $\mathrm{pH}$ $=6.2$ and $\mathrm{pCO}_{2}=1$ atm as a function of calcite growth rate. Light $\mathrm{Ni}$ isotopes are preferentially incorporated into calcite during its coprecipitation, which is likely due to a longer $\mathrm{Ni}-\mathrm{O}$ bond length in calcite compared to that of the $\mathrm{Ni}$ aquo complex. The extent of $\mathrm{Ni}$ isotope fractionation between $\mathrm{Ni}$ in the solid and the aqueous fluid phase increases from -0.3 to $-0.9 \%$ as the calcite growth rate slows from $10^{-7.3}$ to $10^{-8.3} \mathrm{~mol} \mathrm{~m}^{-2} \mathrm{~s}^{-1}$. This behaviour can be attributed to the strong hydration of the $\mathrm{Ni}^{2+}$ aqueous ion. As mineral growth rates depend strongly on the degree of supersaturation of the fluid relative to the mineral, the results of this study suggest that the $\mathrm{Ni}$ isotopic composition of natural calcite can potentially provide insight into the saturation state of seawater with respect to calcite at the time that this mineral formed. In addition, calculations based on our results suggest that the incorporation of $\mathrm{Ni}$ into calcite could be a significant sink of light $\mathrm{Ni}$ in the ocean.

\section{INTRODUCTION}

A large number of past studies have focused on the composition of divalent cations substituted for Ca in calcite and aragonite (Lorens, 1981; Mucci and Morse, 1983; Tesoriero and Pankow, 1996; Lakshtanov and Stipp, 2007; von Allmen et al., 2010). The motivation for such efforts stems from the potential use of the divalent metal compositions of calcium carbonates as proxies of past environmental conditions. Notably as divalent cations substitute for $\mathrm{Ca}$, they record information on the composition of the reactive fluid from which they precipitated (Mavromatis et al. 2013, 2020; Rodler et al. 2015). 
The influence of calcite growth rates on the isotope fractionation of divalent metals have also been investigated for its potential application in paleoceanography (Lemarchand et al., 2004; Tang et al., 2008; Böhm et al., 2012; Schott et al., 2014; AlKhatib and Eisenhauer, 2017; Mavromatis et al., 2019). Indeed, as the rate of attachment of lighter isotopes to growing crystals is faster than that of the heavier isotopes, the isotopic signatures of divalent trace elements in marine calcites can provide insight into calcite growth rate, the saturation state of seawater relative to this mineral and, potentially, the associated $\mathrm{pCO}_{2}$ at the time of this mineral's precipitation. Interestingly, whereas the extent of isotope fractionation of $\mathrm{Sr}$ and $\mathrm{Ba}$ (Tang et al. 2008; Böhm et al. 2012; Mavromatis et al. 2020) increases with increasing calcite growth rates, that of $\mathrm{Mg}$ decreases (Mavromatis et al. 2013). This behavior has been attributed to the differences in the desolvation rates of these metals relative to $\mathrm{Ca}^{2+}$ (Mavromatis et al., 2013). Note that whereas the $\mathrm{Sr}^{2+}$ and $\mathrm{Ba}^{2+}$ desolvation rates are similar to that of $\mathrm{Ca}^{2+}$, the $\mathrm{Mg}^{2+}$ desolvation rate is nearly 4 orders of magnitude slower. This results in the incorporation of partially hydrated $\mathrm{Mg}$ cations into rapidly growing calcite. As a consequence, less isotope fractionation is observed between aqueous $\mathrm{Mg}$ and the $\mathrm{Mg}$ incorporated into calcite as calcite growth rates increase (Mavromatis et al., 2013). It seems, therefore, that by measuring the isotopic compositions of two or more of its divalent metals exhibiting contrasting fractionation behaviors further constraints on the chemical environments in which marine calcites formed could be obtained.

The $\mathrm{Ni}^{2+}$ aquo ion has the slowest exchange rate of water molecules in its hydration sphere among the divalent metals. This exchange rate is $\sim 5$ orders of magnitude slower than that of $\mathrm{Ca}^{2+}$. As with the case of $\mathrm{Mg}^{2+}$, it seems likely that the isotopic fractionation of $\mathrm{Ni}^{2+}$ during its incorporation into the calcite structure will have a distinct and strong dependence on calcite growth rates. The Ni isotope signatures of marine calcites, therefore, have the potential to be a useful proxy of these rates. Evaluation and calibration of this potential proxy requires the quantification $\mathrm{Ni}$ isotope fractionation during its coprecipitation with calcite and the dependence of this fractionation on calcite growth rates. The present study presents the first experimental investigation of $\mathrm{Ni}$ isotope fractionation between aqueous fluids and abiotic calcite as a function of its growth rate at Earth's surface conditions. The results of this study show a clear and systematic variation of the $\mathrm{Ni}$ isotopic composition as a function of the calcite growth rate, demonstrating the potential of $\mathrm{Ni}$ isotope compositions to illuminate the ocean saturation state with respect to calcite and $\mathrm{pCO}_{2}$ at the time of mineral formation.

\section{MATERIAL AND METHODS}




\subsection{Experimental design}

The experiments performed in this study were designed to measure Ni partition coefficients $\left(D_{N i}\right)$ and the isotopic fractionation $\left(\Delta^{60} \mathrm{Ni}_{\text {calcite-fluid }}\right)$ between calcite and its co-existing aqueous fluid by growing Ni-bearing calcite onto calcite seeds. Experiments were performed in mixed flow reactors using the constant addition method, as described in Tesoriero and Pankow (1996) with a few adaptations (see Fig. 1). In this method, the precipitation of Ni bearing calcite is induced by adding two separate aqueous fluids to the reactors, one containing $\mathrm{Ni}$ and $\mathrm{Ca}$ ions and the other containing carbonate ions. When these two fluids are pumped into the reactor, their mixing leads to calcite supersaturation in the aqueous reactor fluid resulting in the growth of $\mathrm{Ni}$ bearing calcite on the calcite seeds. The degree of calcite supersaturation, and consequently the calcite growth rates were modified by varying the inlet fluid flow rates, the calcium and carbonate concentrations of the injected fluids, and the mass of calcite seeds present initially in the reactor. Three modifications to the Tesoriero and Pankow (1996) experimental design were made in this study. First, a peristaltic pump was used to inject fluid into the reactors. Second, Ni was added to the injected fluids at the beginning of the experiments without having first reached steady-state reactor fluid concentrations. Third, $\mathrm{Ni}$ was added to the reactor fluid in some of the experiments before the pumping of the fluids began.

Synthetic high purity Merck EMSURE® calcite was used as seed material in all experiments. This calcite had a surface area of $0.28 \pm 0.03 \mathrm{~m}^{2} / \mathrm{g}$ as determined by triple-point krypton adsorption according to the BET method (Brunauer et al. 1938), using a Quantachrome Autosorb-1MP instrument. Scanning Electron Microscope (SEM) images were obtained of this initial calcite using the JEOL JSM 6700F spectrometer at the Raimond Castaing Center for Microcharacterization in Toulouse, France. These SEM images show the rhombohedral morphology of the initial calcite crystals, as well as intergrowth and agglomeration. The average length of the calcite crystals was about $6 \mu \mathrm{m}$. The composition of these calcite seeds was determined by digestion in concentrated $\mathrm{HCl}$ followed by analysis of the resulting fluid by Atomic Absorption Spectrometry. The Ni concentrations of these fluids was below the detection limit of the analyses, such that the Ni concentration of the seeds was negligible compared to that of the calcite precipitated in the growth experiments. 
All aqueous solutions used in this study were prepared using high purity (>99\%) reagents and deionized MQ water (resistivity 18.2 $\mathrm{M} \Omega \mathrm{cm}^{-1}$ ) obtained from a Millipore system. All acids used during the experiments were double-distilled, and all used commercial reagents were either suprapure or normapure grade. The aqueous Ni stock solution used during this study was prepared by dissolving Sigma-Aldrich, $99.99 \%$, trace metal basis $\mathrm{Ni}\left(\mathrm{NO}_{3}\right)_{2}$ to obtain a $10,000 \mathrm{ppm} \mathrm{Ni}$ solution. adding approximately $2 \mathrm{~g}$ of calcite seeds to a $0.2 \mathrm{~mol} / \mathrm{kg} \mathrm{NaCl}$ aqueous fluid and while bubbling the fluid with 1 atm $\mathrm{CO}_{2}$ for 12 hours. The equilibrated fluid was then separated from the calcite using a Merck Millipore $0.2 \mu \mathrm{m}$ Teflon syringe filter. The pre-equilibrated aqueous fluid then was added together with new calcite seed crystals to a Nalgene polycarbonate reactor. The mass of these initial calcite seed crystals ranged from 0.75 to $4 \mathrm{~g}$. The initial aqueous fluid and the calcite seeds were then allowed to equilibrate overnight while bubbling 1 atm pure $\mathrm{CO}_{2}$ in the reactor fluid. This assured the mineral-fluid system was close to equilibrium prior to starting the fluid flow. After this equilibration step, the two inlet fluids were injected into the reactor at constant rates. The two inlet fluids used during the flow experiments consisted of 1) a $\mathrm{CaCl}_{2}$ and $\mathrm{Ni}\left(\mathrm{NO}_{3}\right)_{2}$ bearing aqueous solution and 2) a $\mathrm{Na}_{2} \mathrm{CO}_{3}$ bearing aqueous solution. The $\mathrm{CaCl}_{2}$ and $\mathrm{NaCO}_{3}$ concentrations of these inlet fluids ranged from 0.06 to $0.2 \mathrm{~mol} / \mathrm{kg}$, and the concentration of $\mathrm{Ni}$ ranged from 4.8 to $28 \mathrm{ppm}$. The inlet fluid $\mathrm{Ca}$ and $\mathrm{Ni}$ concentrations for the experiments are provided in Table 1. The aqueous Ni concentration was kept as low as possible while taking into account the requirements of the isotope measurements, namely that at least $600 \mathrm{ng}$ of $\mathrm{Ni}$ was present in all collected fluid samples. Moreover, the $\mathrm{Na} / \mathrm{Ni}$ ratio of the sampled aqueous fluids was kept lower than 20 so not to hamper the subsequent $\mathrm{Ni}$ chemical separation procedure based on ion exchange chromatography. Consequently $2.6 \mathrm{mg}$ of a sampled $0.2 \mathrm{M} \mathrm{NaCl}$ fluid must contain at least $600 \mathrm{ng}$ of $\mathrm{Ni}$.

The total ionic strength of the inlet fluids was fixed to $0.2 \mathrm{~mol} / \mathrm{kg}$ to be consistent with that of the initial reactive fluid; to adjust their ionic strength, $\mathrm{NaCl}$ was added to these fluids. The two inlet fluids were pumped into the reactor at equal flow rates using a peristaltic pump. The flow rates ranged from approximately 10 to $40 \mathrm{~g}$ /day depending on the experiment; these fluid flow rates were regularly verified during each experiment by weighing the inlet fluid reservoirs. The mass of aqueous fluid in the reactor was kept constant by removing a volume of aqueous fluid 
equal to that added each $24 \mathrm{hrs}$ (or $48 \mathrm{hrs}$ in the case of slower growth rate experiments), so that the fluid volume in the reactor varied by less than $10 \%$ throughout the experiments.

In some coprecipitation experiments, a small volume of the aqueous Ni stock solution was added to the reactive fluid in the reactor at the beginning of the experiments. This was done to accelerate the attainment of steady-state $\mathrm{Ni}$ concentrations in the reactor fluid. The concentration of $\mathrm{Ni}$ added to each reactor at the beginning of an experiment was determined by modeling the $\mathrm{Ni}$ concentration at steady state from the experimental parameters and assuming that the distribution coefficient, $D_{\mathrm{Ni}}$, equaled 1 (Lakshtanov and Stipp 2007). Preliminary experiments showed that there was no effect of adding $\mathrm{Ni}$ at the beginning of the experiment on the reactive fluid $\mathrm{Ni}$ concentration or on the isotopic composition of the $\mathrm{Ni}$ in these fluids at steady state.

The reactor temperature was kept at $25+/-2{ }^{\circ} \mathrm{C}$ using a Fisher thermostatic bath. The calcite seeds were kept in suspension using a Teflon floating stirring bar, which prevents grinding of the calcite against the bottom of the vessel. Fluid $\mathrm{pH}$ and alkalinity were maintained at constant values by constantly bubbling pure $\mathrm{CO}_{2}$ through the rector. To minimize evaporation during the experiments, the $\mathrm{CO}_{2}$ gas was passed through a $0.2 \mathrm{M} \mathrm{NaCl}$ solution before entering the reactor - see Fig. 1 .

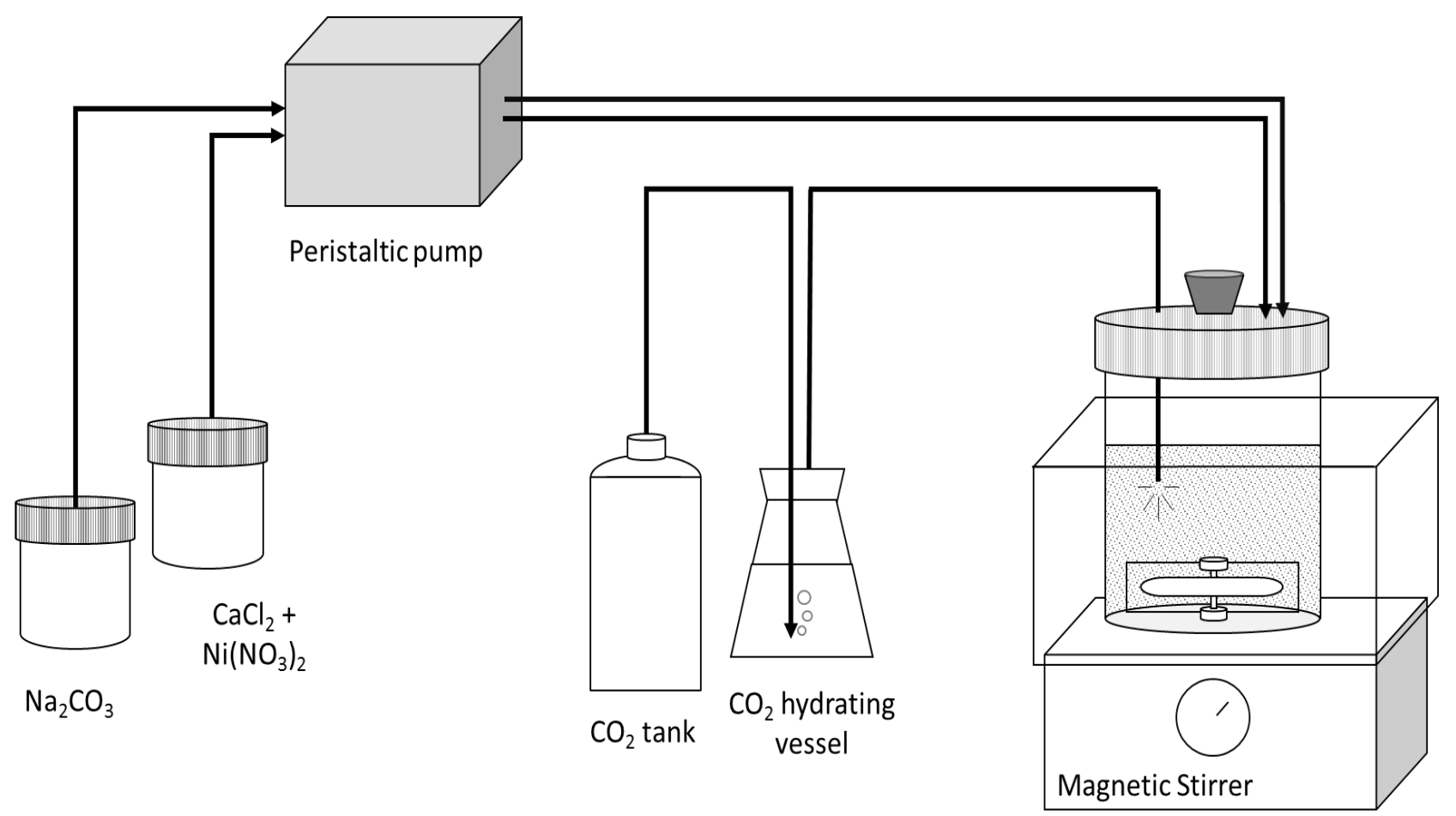


Figure 1 Schematic illustration of the experimental design used for the coprecipitation experiments. The reactor was placed in a thermostatically controlled vessel and the aqueous reactor fluid was mixed using a suspended stirring bar. A constant $\mathrm{CO}_{2}$ partial pressure of $1 \mathrm{~atm}$ was achieved by bubbling pure $\mathrm{CO}_{2}$ into the reactor. Inlet fluids were pumped into the reactor at a constant rate using a peristaltic pump.

Fluids were regularly sampled from the reactor to monitor reaction progress. To avoid removing calcite from the reactor during the experiments, stirring was stopped to allow the solids to settle for a few minutes prior to aqueous fluid sampling. Sampled fluids were immediately filtered through a $0.22 \mu \mathrm{m}$ Merck Millipore Teflon syringe filter. Three sub-samples were taken: one for alkalinity determination, one for dissolved element concentration measurement, and one for nickel isotopic composition analysis. The fluids collected for elemental and for isotopic analysis were acidified shortly after sampling, using double distilled $\mathrm{HNO}_{3}$ for the bulk chemical composition analysis or using distilled $\mathrm{HCl}$ for the isotopic analysis.

Pumping of the input fluids was continued until a steady state fluid composition was attained in the reactor. At steady state, the addition of calcium and nickel via inlet fluid injection is equal to that precipitated as calcite, so the composition of the reactor fluid remains constant. The $\mathrm{pH}$, alkalinity, aqueous $\mathrm{Ca}$ and $\mathrm{Ni}$ concentrations were measured regularly and used to verify the attainment of steady state. Steady state was considered to be reached once three consecutive measurements of the sampled fluids compositions remained constant within analytical uncertainty. Once steady state was confirmed the experiments were stopped. The duration of the experiments ranged from 8 to 21 days.

At the end of each experiment the solids were separated from the reactor fluid via suction filtration using a $0.22 \mu \mathrm{m}$ Teflon filter (Millipore). The solids were rinsed with water to remove any $\mathrm{Ni}$ adsorbed on the calcite surface and allowed to dry at room temperature. To verify the precipitation of calcite during the experiments, the collected solids were examined by X-ray

182 Diffraction (XRD) and SEM. XRD analyses were performed using an INEL CPS-120

183 diffractometer with Co Ka-radiation having a detection limit of $\sim 5 \%$. The obtained diffraction patterns were compared to the characteristic profile for calcite taken from the RRUFF database (Lafuente et al. 2016). A representative XRD pattern of the reaction products is provided in the Supplementary Material. After these analyses, the total mass of collected solids were dissolved using $4 \mathrm{M} \mathrm{HCl}$, which generated a homogeneous fluid sample used for further analyses. 


\subsection{Chemical analysis of the fluid phases}

The alkalinity of collected fluids was measured shortly after sampling via $0.05 \mathrm{M} \mathrm{HCl}$ acidimetric titration using a Schott TA 10 plus volumetric automatic titrator. The measurements were performed following the Gran method (Stumm, 1996) and had an uncertainty of $\pm 1 \%$ with a detection limit of $5 \times 10^{-5} \mathrm{eq} / \mathrm{l}$. The $\mathrm{pH}$ of the reactor fluids was measured in situ using a Mettler Toledo glass $\mathrm{pH}$ electrode calibrated before each measurement using Thermo Fisher buffers $\left(\mathrm{pH}=4.006,6.865\right.$ and 9.183 at $\left.25^{\circ} \mathrm{C}\right)$. The buffers used for electrode calibration were kept in a thermostated bath at the same temperature as the reactors. The uncertainty of the measured $\mathrm{pH}$ values is estimated to be $\pm 0.02 \mathrm{pH}$-units.

The $\mathrm{Ca}$ and $\mathrm{Ni}$ concentrations of all sampled fluids were measured by flame Atomic Absorption Spectrometer (AAS) using a Perking Elmer Analyst 400 with an uncertainty of $\pm 1 \%$ and a detection limit of $7 \times 10^{-7} \mathrm{~mol} / \mathrm{kg}$. Standards were prepared using $1000 \mathrm{ppm} \mathrm{Ca}$ or $\mathrm{Ni}$ standard solutions and an aqueous $2 \% \mathrm{HNO}_{3}$ solution for dilution. This $2 \% \mathrm{HNO}_{3}$ solution was also used to dilute the collected experimental reactor fluid samples for $\mathrm{Ca}$ analysis so that their concentration and $\mathrm{pH}$ fell within the measurement range. Calcium measurements were performed over the 0.5 to $5 \mathrm{ppm}$ range, hence the samples were diluted by a factor of 200 for these analyses. Lanthanum oxide was added to all samples and standards prepared for $\mathrm{Ca}$ analysis to reach a final concentration of $0.409 \mathrm{~g} / \mathrm{kg}$ to avoid anionic chemical interferences. Nickel measurements were performed over the 1 to $10 \mathrm{ppm}$ range. Samples for nickel analysis were measured undiluted and the standards were diluted in an aqueous $\mathrm{NaCl}$ solution having an identical concentration as the samples to avoid potential matrix effects.

\subsection{Calculation of $\mathrm{Ni}$ partition coefficients and calcite growth rates}

The partitioning of a divalent cation, $\mathrm{Me}^{2+}$, between calcite and its coexisting aqueous

214 fluid represents the equilibrium constant of the exchange reaction between $\mathrm{Ca}^{2+}$ and $\mathrm{Me}^{2+}$ in $\left(\mathrm{Ca}_{1-}\right.$ $215 \mathrm{x}_{\mathrm{X}} \mathrm{CeO}_{3}$ solid solutions (see the Appendix). This exchange is commonly described using the 216 Henderson and Kracek (1927) apparent partition coefficient, which implicitly assumes that 217 aqueous $\mathrm{Ca}$ and $\mathrm{Me}$ complexation is negligible and that the activity coefficients of the $\mathrm{CaCO}_{3}$ and $218 \mathrm{MeCO}_{3}$ solid solutions are equal to one. The apparent partitioning coefficient, $D_{N i}$, between calcite and the fluid is thus expressed as 
$D_{N i}=\frac{x_{i *}:}{x_{\text {Lu }}} \frac{[\mathrm{cil}]}{[\cdots i]}$

220

where [Ni] and [Ca] stand for the molal concentrations of $\mathrm{Ni}$ and $\mathrm{Ca}$ in the aqueous fluid, $X_{\mathrm{Ni}}$ and $X_{\mathrm{Ca}}$ refer to the mole fractions of $\mathrm{Ni}$ and $\mathrm{Ca}$ in the solid, respectively.

The mole fraction of $\mathrm{Ni}$ precipitating in the solid at steady state conditions, $X_{\mathrm{Ni}}$ can be calculated in experiments where $\mathrm{Ni}$ is added into a mixed flow reactor from mass balance constraints using

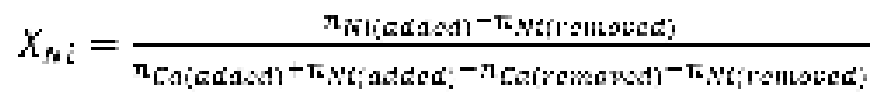

where $n_{\mathrm{Ca}(\text { added })}$ and $n_{\mathrm{Ni}(\text { added })}$ represent the number of moles of $\mathrm{Ca}$ and $\mathrm{Ni}$, respectively, added to the reactor by fluid injection over one day, and $n_{\mathrm{Ca} \text { (removed) }}$ and $n_{\mathrm{Ni} \text { (removed) }}$ stand for the number of moles of $\mathrm{Ca}$ and $\mathrm{Ni}$ respectively removed by reactor fluid sampling during that day.

Calcite growth rates $\left(R_{p}\right)$ at steady state can be calculated using

$R_{p}=\frac{\left[C a_{i n}\right]-\left[C a_{r u m u r c i l}\right]}{F^{\prime} R \cdot S}$

where $\left[\mathrm{Ca}_{\text {in }}\right]$ and $\left[\mathrm{Ca}_{\text {removed }}\right]$ stand for the overall $\mathrm{Ca}$ concentration of the combined inlet fluids and that in the fluids removed from the reactor during sampling, $F R$ refers to the fluid flow rate, and $S$ denotes the total surface area of calcite in the reactor. The specific surface area of precipitated calcite at the end of the experiments was identical, within uncertainty, to that of the original calcite seeds. Note that rates calculated using Eq. 3 do not take account of $\mathrm{Ni}$ incorporated into the precipitated calcite, as its mass is negligible compared to that of Ca.

\subsection{Isotopic analysis}

Samples were prepared for $\mathrm{Ni}$ isotopic analyses by ion exchange chromatography. All collected steady state reactor fluid and solid samples, as well as the starting Ni-components and some standards aliquots were processed identically except for a calcium separation step, which was performed only on the fluids generated from the aqueous $\mathrm{HCl}$ digestion of the solid calcite samples. This calcium separation step preceded the ion exchange chromatography process. During this initial separation stage, the calcium was precipitated as $\mathrm{CaF}_{2}$ to reduce the amount of dissolved calcium loaded onto the columns to avoid surpassing the resin capacity. 
For this calcium separation a $100 \mu \mathrm{L}$ aliquot of the fluid generated from calcite digestion was first evaporated. Chloride was then replaced by fluoride by taking up this residue in $5 \mathrm{~mL}$ of a $1 \mathrm{M}$ aqueous $\mathrm{HF}$ solution, refluxing the sample at $120{ }^{\circ} \mathrm{C}$ for $2 \mathrm{hrs}$, and then evaporating it. This process was repeated a second time except for the evaporation step. The resulting liquids were then centrifuged for 10 minutes at $4500 \mathrm{rpm}$ and the supernatant was placed in a Teflon beaker while the residue was rinsed with water. After a vigorous agitation, the residue bearing water was again centrifuged. The resulting supernatant was added to the previously collected supernatant in the Teflon beaker. The combined liquid samples were evaporated and then taken up in $2 \mathrm{M} \mathrm{HCl}$. Afterwards, these fluids were treated identically as the originally fluid samples. To ensure that this $\mathrm{CaF}_{2}$ precipitation step has no effect on the Ni isotope composition, an Aldrich Ni standard was added to a carbonate sample devoid of $\mathrm{Ni}$. This Ni-doped sample was then processed the same way as any other solid samples: it displays the same isotope composition as the original unprocessed Ni standard.

Nickel was separated from other matrix elements prior to isotope analysis using a 5 step separation procedure adapted from Quitté and Oberli (2006). The details of this separation are described in Castillo Alvarez et al. (2020). The first two steps require the Bio-Rad AG 1-X8 anion exchange resin and aimed to remove $\mathrm{Fe}$ and $\mathrm{Zn}$, the main isobaric interferences for $\mathrm{Ni}$. The third step was performed using a Triskem Nickel specific resin and is based on the complexation of $\mathrm{Ni}$ with Dimethylglyoxime (DMG) to form Ni-DMG. The fourth step used the Bio-Rad AG50W-X8 cation exchange resin to purify the sample. The last step uses the Bio-Rad AG1-X8 anion exchange resin to remove the Fe introduced during the previous steps. The fluid recovered after the completed separation procedure was dried and the final residue retained for analysis.

This residue was dissolved in $0.1 \mathrm{M} \mathrm{HCl}$ for isotope analysis. Nickel isotope measurements were performed at the Observatoire Midi Pyrenees analytical platform in Toulouse France, using a Thermo-Finnigan Neptune multi-collector inductively coupled plasma mass spectrometer (MCICPMS). The MC-ICPMS was equipped with an Apex desolvating system connected to a glass nebulizer, and fitted with a standard sample cone and a X skimmer cone. Samples were measured in medium resolution mode, using the sample-standard bracketing technique and $\mathrm{Cu}$ doping to correct for mass bias. The Ni concentration of the measured samples was $200 \mathrm{ppb}$ while the $\mathrm{Cu}$ concentration was $100 \mathrm{ppb}$. The $2 \sigma$ (two standard deviations) of the $\delta^{60} \mathrm{Ni}$ measurements was 
and $0.188 \%$. Some of this variation may be due to minor Fe and/or $\mathrm{Zn}$ contamination present in some samples. As mentioned above, a Sigma Aldrich Ni standard was processed through the whole chemical separation procedure together with every set of experimental samples to verify that no fractionation occurred during the Ni separation process. Also, to confirm the suitability of this procedure to separate $\mathrm{Ni}$ from a calcium carbonate matrix, a test was performed in which some Sigma Aldrich Ni standard was added to an originally $\mathrm{Ni}$-free calcite saturated $0.2 \mathrm{M} \mathrm{NaCl}$ aqueous solution, representative of the experimental matrix, and to the calcite seed. They were then processed through the chemical separation steps in the same way the samples were processed. No isotope fractionation was observed for the processed standards relative to the corresponding original standards, confirming the quality of the chemical separation procedure. Blanks of the ion exchange chromatography were checked for every set of samples processed. They were measured using an Agilent 7700 quadrupole ICP-MS, with an associated analytical uncertainty estimated to be $\pm 5 \%$. The measured blanks vary between 0.85 and $1.93 \mathrm{ng}$ of $\mathrm{Ni}$, which is negligible compared to the amount of $\mathrm{Ni}$ in the samples (at least $600 \mathrm{ng}$ ).

Isotope compositions in this paper are presented in delta notation, $\delta^{60} \mathrm{Ni}$, corresponding to the ratio of ${ }^{60} \mathrm{Ni}$ relative to ${ }^{58} \mathrm{Ni}$ normalized to the Aldrich ICP standard. This standard was used rather than the certified SRM986 standard as it is the in-house standard for which we have a welldefined value and long-term reproducibility. The results of this study are not affected by the identity of the standard used, as we are interested in difference in the Ni isotope composition of the solid versus the fluid $\left(\Delta^{60} \mathrm{Ni}_{\text {solici-riaid }}\right)$ rather than absolute value of these isotopic compositions. This isotopic offset between $\mathrm{Ni}$ in the solid and the fluid phase is defined by

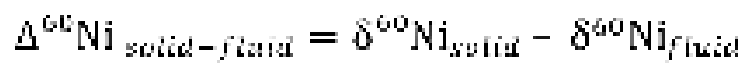

where $\delta^{60} \mathrm{Ni}_{s, i t i}$ and $\delta^{60} \mathrm{Ni}_{\text {fluic }}$ refer to the measured nickel isotopic composition of the subscripted phase corresponding to the ratio of ${ }^{60} \mathrm{Ni}$ relative to ${ }^{58} \mathrm{Ni}$ normalized to the in-house standard.

\section{RESULTS}

\subsection{Mineralogy and chemical composition of the precipitated phases}

X-ray diffraction (XRD) patterns of the solids recovered from the reactors after all experiments appear identical to the original calcite seeds. Some representative Scanning Electron 
Microscope (SEM) images of these post-experiment solids are shown in Fig. 2. The postexperiment solids maintained the characteristic calcite rhombic morphology. No aragonite needles were detected by this analysis.
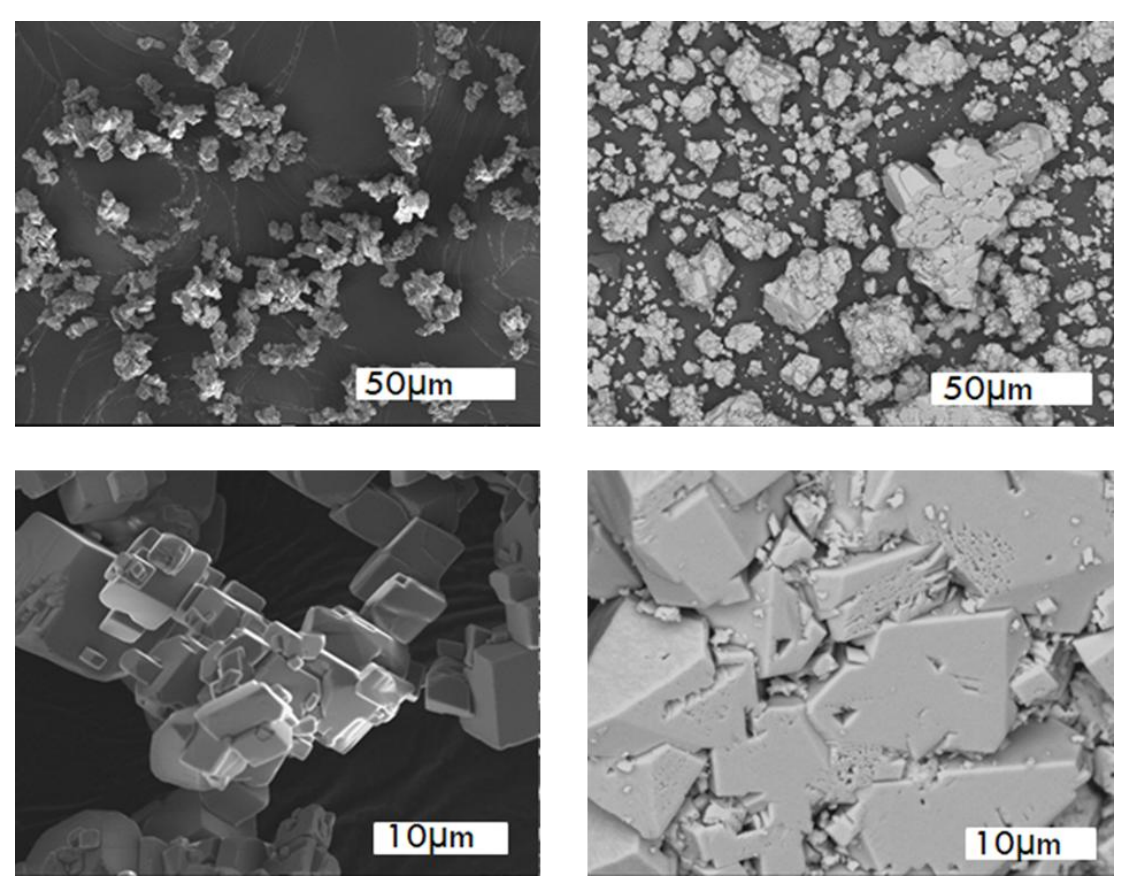

Figure 2 SEM images of the initial calcite seed material (left) and of the calcite recovered after experiment $C 17$ (right). The scales of the images are provided in the figure.

\subsection{Chemical composition of the reactive fluids}

A total of 12 coprecipitation experiments were performed in this study. A summary of the experimental conditions and the steady state reactive fluid compositions of all experiments is provided in Table 1. Steady-state aqueous $\mathrm{Ca}$ concentrations and alkalinities were usually achieved within 3 days after the start of each experiment. A significantly longer time (up to 21 days), however, was required to attain steady-state aqueous Ni concentrations. The time to reach steady state depends on the $\mathrm{Ca}$ and $\mathrm{Ni}$ concentrations in the inlet fluids and on the inlet fluid flow rate. Figure 3 shows a representative plot of the temporal evolution of aqueous fluid compositions during one of the flow experiments performed in this study. In this experiment, Ni was not initially present in the reactor. The reactive fluid reaches a steady state $\mathrm{Ni}$ composition of $11.25 \times 10^{-6} \mathrm{~mol} / \mathrm{kg}$ after approximately 5 days. The calcium concentration is relatively stable 
334 throughout the experiment and has a steady state value of $0.014 \mathrm{~mol} / \mathrm{kg}$. The alkalinity also 335 remained almost unchanged and has a steady state concentration of $0.027 \mathrm{~mol} / \mathrm{kg}$. Note the initial 336 fluids in the reactor were pre-equilibrated with calcite, which fixed the fluid Ca concentration and 337 alkalinity at the start of the experiment (see above).

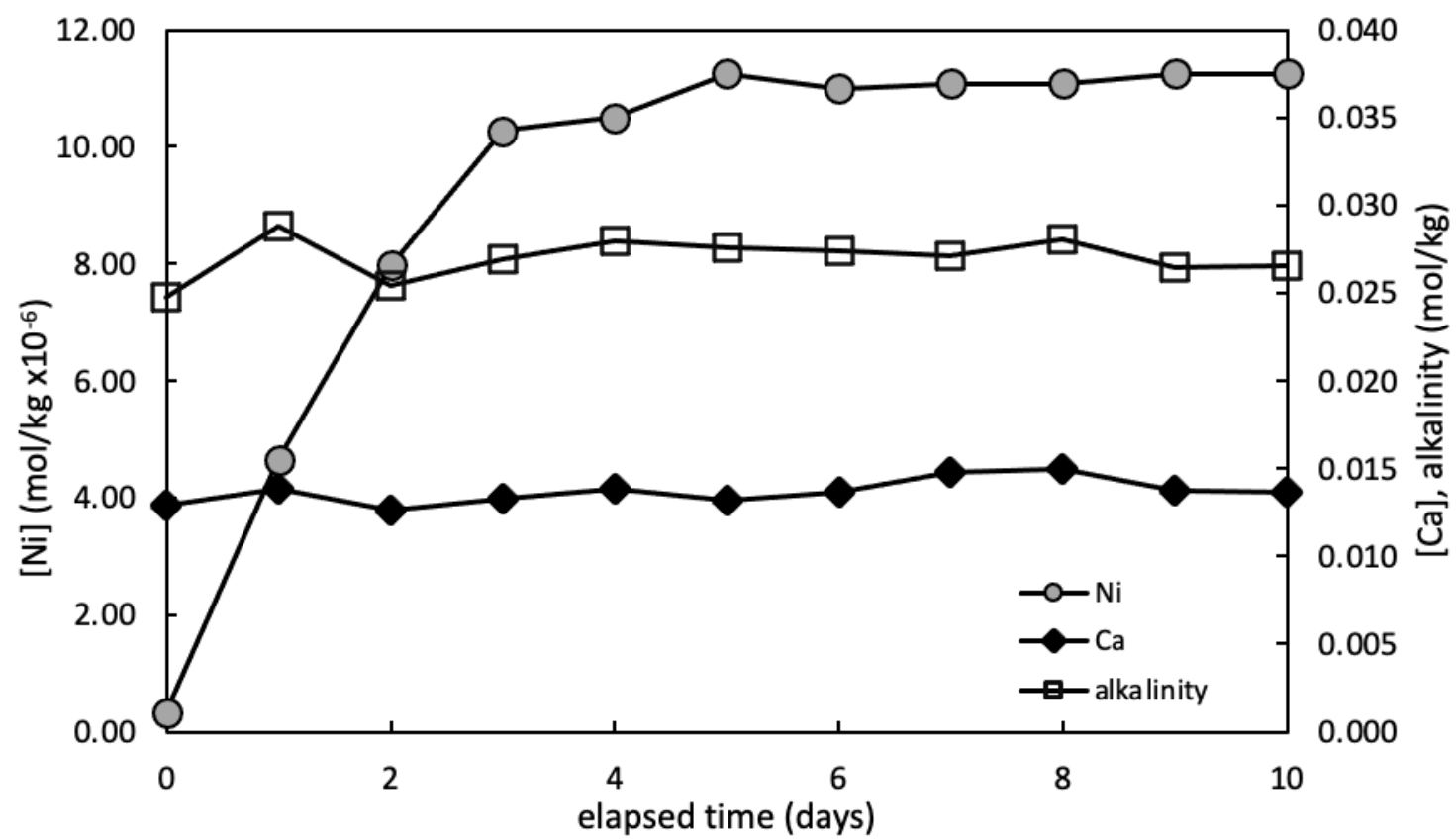

Figure 3 Reactive fluid $\mathrm{Ni}$ and $\mathrm{Ca}$ concentrations, and alkalinity during experiment C15. These results illustrate a typical reactor fluid evolution during a flow experiment performed in this study. The black diamonds show the temporal evolution of calcium, while alkalinity is shown by the open squares. Both are consistent with the right scale. Nickel concentrations are represented by the grey circles and its scale is shown on the left. Analytical uncertainty is included in symbol size.

\subsection{Mineralogy and composition of the precipitated phases}

The mole fraction of nickel, $X_{\mathrm{Ni}}$, in the precipitated calcite was calculated from the steady state reactive fluid compositions using eq. 2. The mole fraction of $\mathrm{Ni}$ in calcite is plotted as a function of the corresponding aqueous $\left[\mathrm{Ni}^{2+}\right]$ to $\left[\mathrm{Ca}^{2+}\right]$ ratio in Figure 4. 


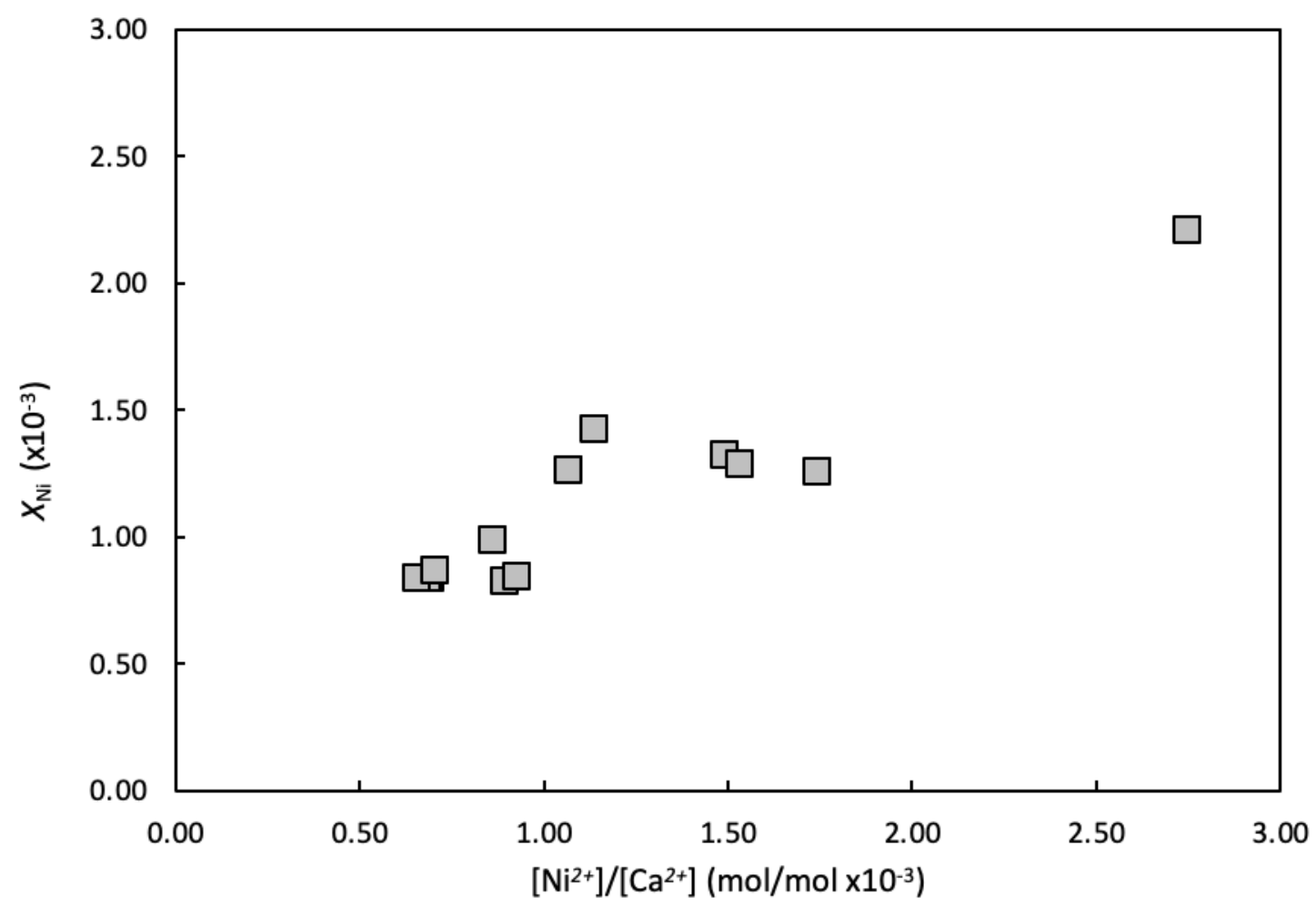

Figure 4 Mole fraction of $\mathrm{Ni}$ in calcite, $X_{N i}$, as a function of the molar $\left[\mathrm{Ni}^{2+}\right]$ to $\left[\mathrm{Ca}^{2+}\right]$ ratio of the reactor fluid at steady state in all experiments performed in this study. The uncertainty associated with these measurements is included within the symbol size.

\subsection{Ni partitioning between calcite and fluid $D_{\mathrm{Ni}}$}

The nickel partition coefficient, $D_{\mathrm{Ni}}$, was calculated from measured concentrations of $\mathrm{Ni}$ in the reactor fluid and solid after steady state was attained, using eq. 1. The measured $\mathrm{Ni}$ partition coefficients range from 0.73 to 1.29 with an average value of $1.09 \pm 0.36$. The corresponding calcite growth rates, determined using eq. 3 , varied from $1.22 \times 10^{7}$ to $2.72 \times 10^{9}$ mol $\mathrm{m}^{2} \mathrm{~s}^{-1}$. No effect of the calcite growth rate on the partition coefficient is evident (see Fig. 5). 


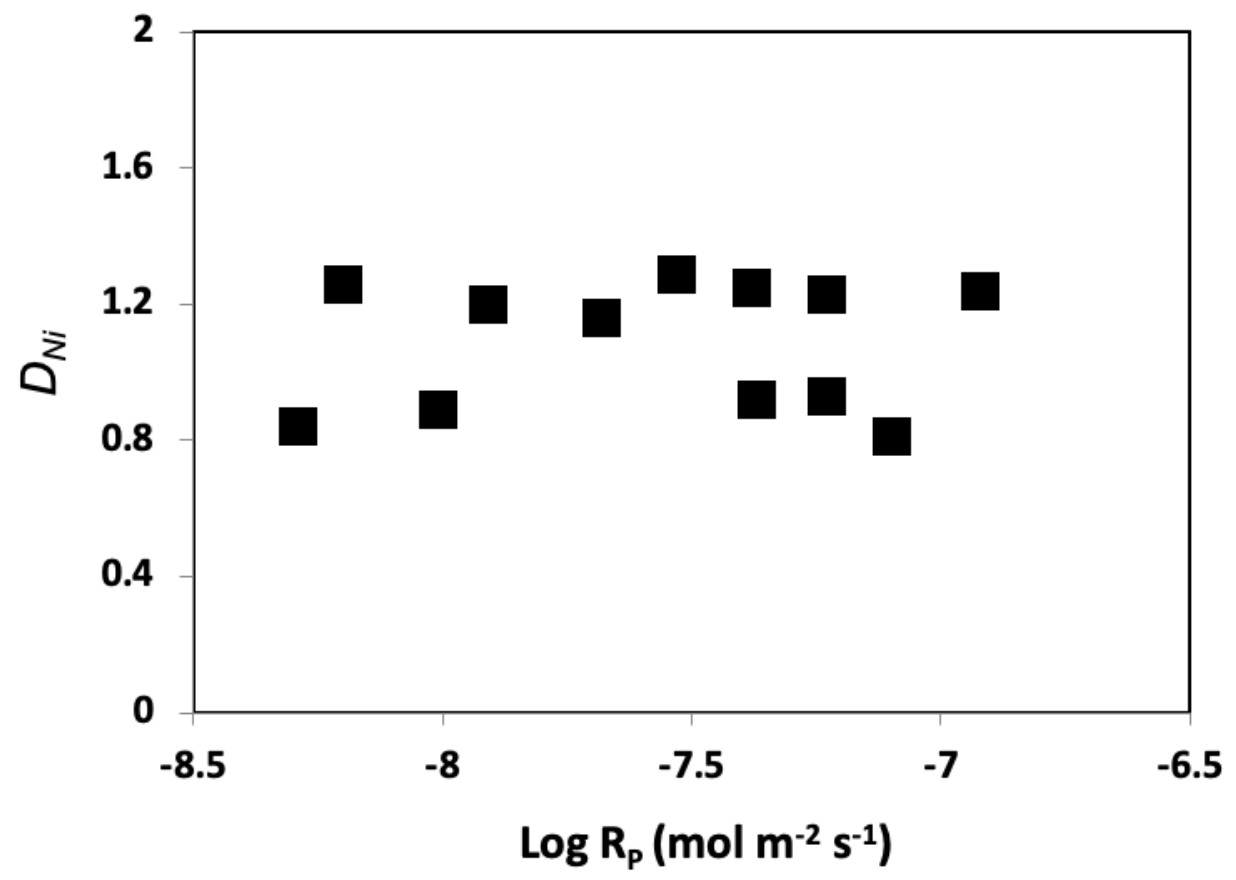

Figure 5 Measured nickel partition coefficients, $D_{N i}$, as a function of the logarithm of the calcite growth rate $\mathrm{R}_{\mathrm{p}}$. The analytical uncertainty associated with these measurements is included within the symbol size.

Table 1 Summary of the calculated calcite growth rates, reactor fluid compostions and partition coefficients generated in the present study. The values of $[\mathrm{Ca}]_{\text {inlet }}$ and $[\mathrm{Ni}]_{\text {inlet }}$ refer to the indicated elemental concentration of the combined two injection fluids.

\begin{tabular}{|c|c|c|c|c|c|c|c|c|c|c|}
\hline Expt. & $\underset{\mathrm{s}^{-1}}{\log \mathrm{R}_{p_{2}}}$ & $\begin{array}{l}{[\mathrm{Ca}]_{\text {inlet }}} \\
\mathrm{mol} / \mathrm{kg}\end{array}$ & $\begin{array}{l}{[\mathrm{Ni}]_{\text {inlet }}} \\
\mathrm{mol} / \mathrm{kg} \\
\times 10^{4}\end{array}$ & $\begin{array}{l}\text { Initial } \\
\text { seed } \\
\text { Mass, g }\end{array}$ & $\mathrm{pH}$ & $\begin{array}{l}\text { Alkalinity } \\
\mathrm{Mol} / \mathrm{kg}\end{array}$ & $\begin{array}{c}{[\mathrm{Ni}]_{s \mathrm{~s}}{ }^{\mathrm{a}}} \\
\mathrm{mol} / \mathrm{kg} \\
\times 10^{5}\end{array}$ & $\begin{array}{l}{[\mathrm{Ca}]_{{ }_{s s}{ }^{a}}} \\
\mathrm{~mol} / \mathrm{kg}\end{array}$ & $\begin{array}{c}X_{\mathrm{Ni}} \\
(\mathrm{mol} \%) \\
\left.\times 10^{3}\right)\end{array}$ & $D_{\mathrm{Ni}}$ \\
\hline C15 & -7.23 & 0.21 & 1.75 & 1.5 & 6.00 & 0.027 & 1.13 & 0.014 & 0.84 & 1.23 \\
\hline C16 & -7.23 & 0.21 & 1.75 & 1.5 & 5.99 & 0.028 & 1.24 & 0.014 & 0.83 & 0.93 \\
\hline C17 & -6.92 & 0.21 & 1.75 & 0.75 & 6.10 & 0.031 & 7.16 & 0.011 & 0.84 & 1.24 \\
\hline C18 & -7.53 & 0.21 & 1.75 & 3.0 & 6.05 & 0.028 & 8.26 & 0.013 & 0.84 & 1.29 \\
\hline C19 & -8.01 & 0.06 & 0.82 & 1.5 & 6.08 & 0.028 & 2.20 & 0.015 & 1.33 & 0.89 \\
\hline $\mathrm{C} 23$ & -7.10 & 0.21 & 4.77 & 3.0 & 6.07 & 0.027 & 6.15 & 0.022 & 2.21 & 0.81 \\
\hline C26 & -7.38 & 0.20 & 1.70 & 2.0 & 6.12 & 0.029 & 0.84 & 0.012 & 0.88 & 1.25 \\
\hline $\mathrm{C} 27$ & -7.91 & 0.10 & 1.21 & 2.0 & 6.34 & 0.037 & 2.57 & 0.024 & 1.27 & 1.20 \\
\hline C29 & -8.20 & 0.06 & 0.82 & 2.6 & 6.44 & 0.029 & 1.47 & 0.013 & 1.43 & 1.26 \\
\hline C31 & -8.29 & 0.06 & 0.81 & 2.0 & 6.17 & 0.030 & 2.96 & 0.019 & 1.29 & 0.84 \\
\hline C36 & -7.68 & 0.07 & 0.68 & 2.2 & 6.11 & 0.032 & 0.98 & 0.011 & 1.00 & 1.16 \\
\hline C37 & -7.37 & 0.20 & 1.70 & 4.0 & 6.01 & 0.030 & 1.03 & 0.011 & 0.85 & 0.92 \\
\hline
\end{tabular}

373 a) the subscript ss refers to the indicated concentration reactor fluid concentration at steady state 


\section{5 $\mathrm{Ni}$ isotope fractionation during calcite growth}

The isotopic compositions of reactor fluids and precipitated solids at steady state are compiled in Table 2. These values were used to calculate the $\Delta^{60} \mathrm{Ni}_{\text {calcite-fluid }}$ values depicted as a

378 function of calcite growth rate in Fig. 6. The negative values of $\Delta^{60} \mathrm{Ni}_{\text {calcite-fluid reflect the }}$ preferential incorporation of light $\mathrm{Ni}$ isotopes in the precipitated calcite. The values of the $\mathrm{Ni}$ fractionation range from -0.13 to $-0.93 \%$. The extent of $\mathrm{Ni}$ isotope fractionation during $\mathrm{Ni}$ incorporation into calcite decreased with increasing carbonate growth rates.

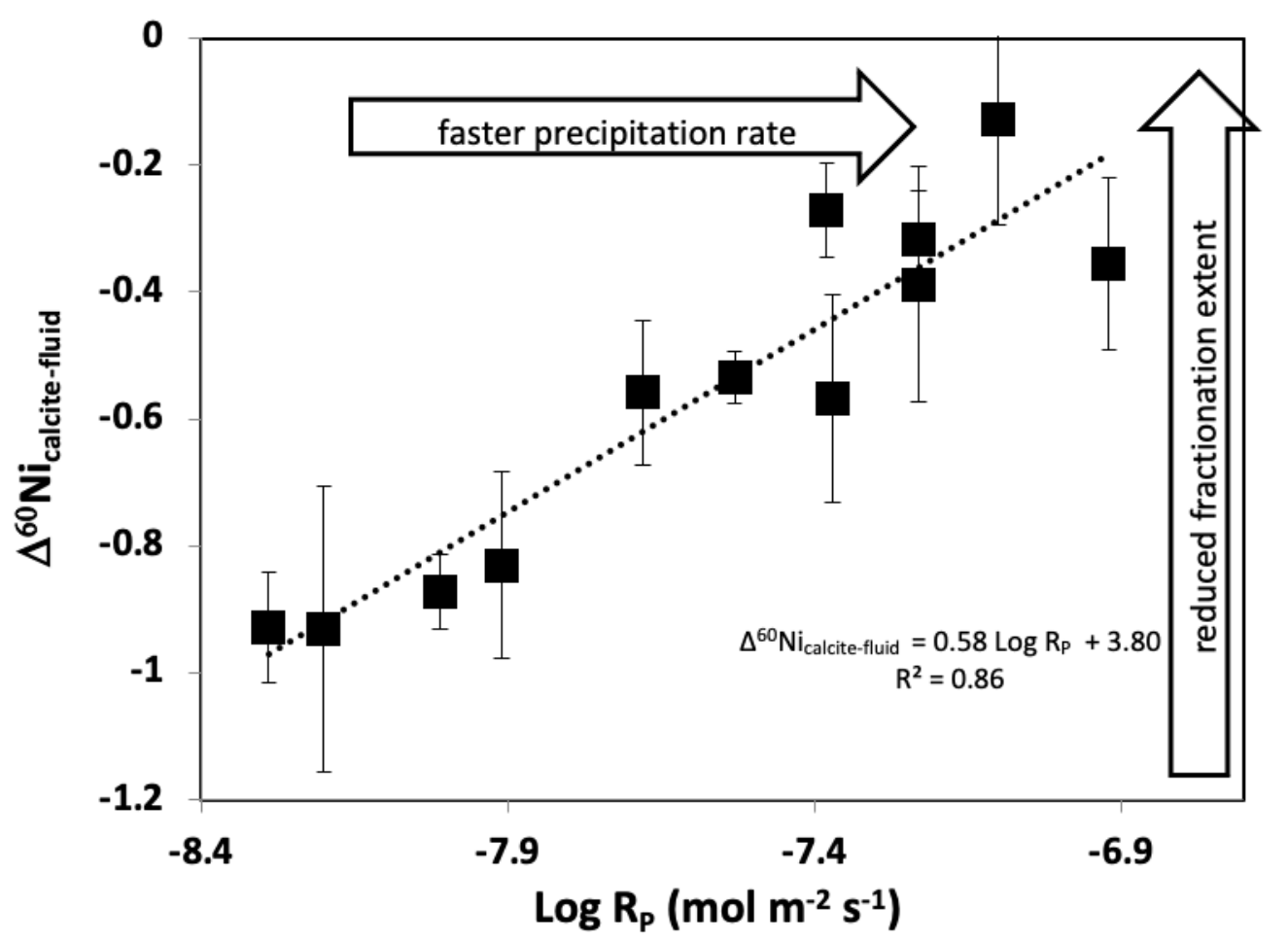

382

Figure $6 \mathrm{Ni}$ isotope fractionation between precipitated Ni bearing calcite and the reactor fluid as a function of the calcite growth rate. The error bars represent 2 standard deviations. The dotted line shows a linear regression of the data. 
Table 2 Results of isotopic analysis of fluids and solids recovered from the coprecipitation experiments and the associated fractionation.

391

392

\begin{tabular}{|c|c|c|c|c|c|c|c|}
\hline Label & $\log R_{p}$ & $\begin{array}{c}\delta^{60} \mathrm{Ni}_{\text {fluid }} \\
\% \text { o }\end{array}$ & $2 \sigma$ & $\begin{array}{c}\delta^{60} \mathrm{Ni}_{\text {calcite }} \\
\% \text { o }\end{array}$ & $2 \sigma$ & $\begin{array}{c}\Delta^{60} \mathrm{Ni}_{\text {calcite-fluid }} \\
\% \text { o }\end{array}$ & $2 \sigma$ \\
\hline inlet & & -0.438 & 0.016 & & & & \\
\hline C15 & -7.23 & -0.364 & 0.032 & -0.681 & 0.070 & -0.317 & 0.077 \\
\hline C16 & -7.23 & -0.264 & 0.116 & -0.652 & 0.144 & -0.388 & 0.185 \\
\hline C17 & -6.92 & -0.319 & 0.134 & -0.675 & 0.026 & -0.356 & 0.136 \\
\hline C18 & -7.53 & -0.189 & 0.038 & -0.724 & 0.016 & -0.535 & 0.041 \\
\hline C19 & -8.01 & -0.333 & 0.052 & -1.206 & 0.027 & -0.873 & 0.059 \\
\hline $\mathrm{C} 23$ & -7.10 & 0.107 & 0.125 & -0.021 & 0.110 & -0.128 & 0.167 \\
\hline C26 & -7.38 & -0.457 & 0.054 & -0.728 & 0.049 & -0.271 & 0.073 \\
\hline $\mathrm{C} 27$ & -7.91 & -0.211 & 0.068 & -1.041 & 0.131 & -0.830 & 0.148 \\
\hline C29 & -8.20 & -0.203 & 0.125 & -1.134 & 0.188 & -0.931 & 0.226 \\
\hline C31 & -8.29 & -0.179 & 0.024 & -1.108 & 0.084 & -0.929 & 0.087 \\
\hline C36 & -7.68 & 0.054 & 0.096 & -0.504 & 0.061 & -0.558 & 0.114 \\
\hline C37 & -7.37 & -0.124 & 0.104 & -0.692 & 0.125 & -0.568 & 0.163 \\
\hline
\end{tabular}

393

394

395

\section{DISCUSSION}

396

397

398

399

400

401

402

403

404

405

406

407

408

409

\subsection{Ni distribution coefficient between calcite and the aqueous fluid}

The Ni mole fraction $\left(X_{\mathrm{Ni}}\right.$, Fig. 4$)$ in the precipitated calcite at the end of all experiments displays a positive correlation with the $\mathrm{Ni}^{2+}$ to $\mathrm{Ca}^{2+}$ concentration ratio with a partition coefficient of $1.09 \pm 0.36$. This behavior is similar to that reported in literature. The partition coefficient of $\mathrm{Ni}$ has also been experimentally determined during its incorporation into foraminiferal calcite, where $D_{N i}$ values ranged from 0.4 to 2 with an average of $1 \pm 0.5$ (Munsel et al. 2010). Also, several studies report partition coefficients from studies performed on abiogenic calcite. For dilute solid solutions $\left(X_{\mathrm{Ni}}<0.001\right)$, the Ni partition coefficient $D_{N i}$, was reported to be about 3.5 by Wang and Xu (2001) and between 0.1 and 6 by Curti (1999). Carlson and Aalto (1997) reported this partition coefficient to be about 2 using liquid scintillation counting. Lakshtanov and Stipp (2007) measured the partition coefficient of $\mathrm{Ni}$ between an aqueous fluid and calcite at various carbonate growth rates. These authors used synthetic calcite seeds and worked at ionic strengths between 0.06 and 0.84 . They reported a partition coefficient value equal to $1.04 \pm 0.11$ that is in excellent agreement with the value determined in this study. 
The partition coefficient, $D_{N i}$, measured in this study can be compared to the values of the equilibrium partition coefficient, $\mathrm{D}_{\mathrm{Ni}}$, derived from the thermodynamics of solid solutions and the solubility products of the two end-members, $\mathrm{CaCO}_{3}$ and $\mathrm{NiCO}_{3}$ generated from (see the appendix),

$$
\mathrm{D}_{\mathrm{Ni}}=\frac{K_{\text {culcils }}}{K_{\text {sico }}}
$$

where $K_{\text {tatcite }}$ and $K_{\mathrm{i} i \mathrm{ic}} \mathrm{v}_{\mathrm{s}}$ refer to the equilibrium constants for the calcite and $\mathrm{NiCO}_{3}$ hydrolysis.

Using $K_{\text {tatcite }}=8.48$ (Minteqv4 data base; Parkhurst and Appelo, 2013) and $p K_{\text {watcos }}=11.01$ (for gaspeite as reported by Gamsjäger et al., 2001 and corrected for the $\mathrm{CO}_{2}$ dissolution reaction using data from the Minteqv4 database), Eq. 5 yields a $D_{\mathrm{Ni}}$ value of 360 , which is much higher than that reported in the present study. Similarly, using the semi-empirical relation proposed by Rimstidt et al. (1998; see the appendix),

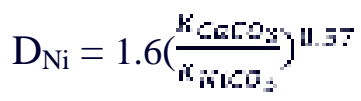

yields a value equal to 46. However, assuming that the end-member of the solid solution is

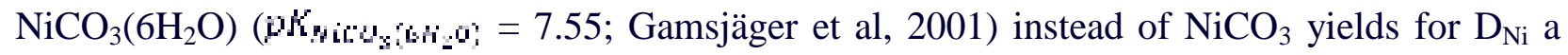
value of 0.14 and 0.52 using Eq. 5 and 6, respectively. These values are in good agreement with the experimental values of this study and of Lakshtanov and Stipp (2007), which strongly suggests, in accord with $\mathrm{Ni}$ isotope data, that the nickel incorporated in calcite during our experiments is solvated.

Our data exhibit no systematic variation of $D_{\mathrm{Ni}}$ as a function of the calcite growth rate. This observation together with $D_{\mathrm{Ni}}=1$ is consistent with identical incorporation rates of $\mathrm{Ni}$ and Ca into the growing calcite crystal (Rimstidt et al., 1998) and an equal affinity of $\mathrm{Ni}^{2+}$ for the fluid and calcite lattice. This observation also indicates the $\mathrm{Ni}$ concentration in calcite bulk crystal is the same as this concentration and in the distorted/hydrated thin layer present at the crystal surface, in accord with Watson's (2004) growth entrapment model. This behavior contrasts with that of i) the alkaline earth metals $(\mathrm{Mg}, \mathrm{Sr}, \mathrm{Ba})$, which exhibit a greater affinity for the fluid than the crystal $(D$ < 1) and whose partition coefficients increase with increasing calcite growth rate and ii) the divalent transition metals ( $\mathrm{Cd}, \mathrm{Mn}, \mathrm{Zn}, \mathrm{Co})$, whose greater affinity for the crystal than the fluid ( $D$ $>1$ ) leads to a decrease of their partition coefficients with increasing calcite growth rate (Watson, 2004; Mavromatis et al., 2013). 
Partition coefficients in nature are similar to those found in this study. For example, the Ni concentration in carbonates from the Peru margin range from 2.2 to $3.9 \mathrm{ppm}$ (Ciscato et al. 2018).

547 Combining these values with the average seawater concentrations of $\mathrm{Ni}(0.8 \mathrm{nmol} / \mathrm{kg}$; Sohrin and 548 Bruland, 2011) and Ca (0.01 mol/kg; Dickson and Goyet, 1994), leads to a $D_{\mathrm{Ni}}$ value ranging from 4.83 to 8.56 , which is relatively close to that measured in this study

The greater the equilibrium partition coefficient, the more affinity an element has for the solid. The partition coefficients calculated for $\mathrm{Ni}$ in the present study indicate that its incorporation into calcite is moderate. Out of the divalent metals, $\mathrm{Be}, \mathrm{Mg}$ and $\mathrm{Ba}$ have lower partition coefficients and thus a lower affinity for calcite (Pingitore and Eastman 1984; Tesoriero and Pankow 1996; Rimstidt et al. 1998; Saulnier et al. 2012) than Ni. On the other hand, Mn, Fe, $\mathrm{Cu}$ and $\mathrm{Zn}$ have higher partition coefficients than $\mathrm{Ni}$, and thus a higher affinity for calcite (Kitano et al. 1980; Lorens 1981; Dromgoole and Walter 1990; Marchitto 2011). In contrast, rare earth elements incorporate more strongly into calcite, with partition coefficient values of up to 4000 (Zhong and Mucci 1995; Webb and Kamber 2000; Voigt et al. 2017). This likely results from the sixfold coordination of most REEs in the calcite calcium site (Elzinga et al., 2002) with an ionic radii close to that of $\mathrm{Ca}^{2+}\left(\mathrm{r}_{\text {io }} \sim 1.0 \AA\right)$, unlike that of $\mathrm{Ni}^{2+}\left(\mathrm{r}_{\text {io }}=0.69 \AA\right)$. Note, however, that the incorporation of $\mathrm{REE}^{3+}$ ions into the calcite structure, unlike that of divalent metals, does not proceed via a simple $\mathrm{Ca}^{2+}-\mathrm{REE}^{3+}$ exchange reaction but requires the associated incorporation of a monovalent cation (i.e. $\mathrm{Na}^{+}$in $\mathrm{NaCl}$ or seawater solutions, Marques Fernandes et al., 2008; Voigt et al., 2017).

\subsection{Controls on $\mathrm{Ni}$ isotope compositions in calcite}

Why are lighter Ni isotopes are preferentially incorporated into calcite?

Equilibrium isotope fractionation was not achieved during our experiments. The dependence of $\Delta^{60} \mathrm{Ni}_{\text {calcite.-fluid }}$ on calcite growth rate shown in Fig. 6, however, shows that $\Delta^{60} \mathrm{Ni}_{\text {calcite.-fluid }}$ decreases with decreasing growth rate and suggests that the equilibrium $\Delta^{60} \mathrm{Ni}_{\text {calcite.-fluid }}$ is likely $\leq$ $1.0 \%$, lower than that observed for the lowest calcite growth rate of this study $\left(10^{-8.3} \mathrm{~mol} / \mathrm{cm}^{2} \mathrm{~s}\right)$. The observed enrichment in calcite of light $\mathrm{Ni}$ isotopes is likely due to differences in the $\mathrm{Ni}$ structural environment, notably the Ni-O bond length in the $\mathrm{Ni}$ aquo ion compared to that in $\mathrm{Ni}$ bearing calcite. Nickel is in octahedral coordination in its aquo ion, in gaspeite $\left(\mathrm{NiCO}_{3}\right)$ and when incorporated as a trace metal in calcite (Varadwaj et al., 2008; Pertlik, 1986; Zavarin and Doner, 
1999). Reported Ni-O bond lengths of the Ni aquo ion range from 2.05 to $2.07 \AA$ (Caminiti et al., 1977; Sandstrom, 1979; Magini et al., 1982; Fujii et al., 2011). There has been, however, no direct measurments of the Ni-O bond length in calcite. The Ni-O bond length in gaspeite has been reported to be $2.076 \AA$ (Pertlik 1986). Because the Ca-O bond length in calcite (2.36 $\AA$; Reeder 1990) is significantly longer than the $\mathrm{Ni}-\mathrm{O}$ bond length in gaspeite, it seems likely the Ni-O bond in Ni-bearing calcite is larger than that in gaspeite. Although there is no published data on the Ni$\mathrm{O}$ bond length in $\mathrm{Ni}^{2+}$-doped calcite, an analogy can be made based on zinc and cobalt bearing calcite. The $\mathrm{Zn}-\mathrm{O}$ and $\mathrm{Co}-\mathrm{O}$ bond lengths in the pure zinc and cobalt carbonates, smithsonite and spherocobaltite, are identical and equal to $2.11 \AA$ (Reeder et al. 1999), whereas these bond lengths in Zn- and Co-doped calcites are $2.15 \AA$ and $2.16 \AA$, respectively (Reeder et al., 1999). It seems reasonable, therefore, that the $\mathrm{Ni}-\mathrm{O}$ bond length in calcite is approximately equal to $2.11 \AA$ or $\sim 0.05 \AA$ larger than that in the nickel aquo complex. As longer bond distances favor lighter isotopes (Criss, 1999; Schauble, 2004), this difference is likely a major factor in the Ni isotope fractionation between aqueous $\mathrm{Ni}$ and $\mathrm{Ni}$ in the calcite structure observed in this study. It should be pointed out that the substitution of $\mathrm{Ca}$ ions in the calcite lattice by partially solvated $\mathrm{Ni}$ instead of anhydrous $\mathrm{Ni}$ with the subsequent protonation of oxygens does not lead to a sufficient change in $\mathrm{Ni}-\mathrm{O}$ bond length to reverse the preferential enrichment of the solid phase in light $\mathrm{Ni}$ isotopes.

Note that nickel adsorbed at the calcite-fluid interface was found to have a $\Delta^{60} \mathrm{Ni}_{\text {calcite-fluid }}=$ $-0.49 \%$ (Castillo Alvarez et al., 2020), an isotope fractionation significantly smaller in magnitude than the equilibrium fractionation value of $\Delta^{60} \mathrm{Ni}_{\text {calcite-fluid }} \leq-1.0 \%$ observed in this study for coprecipitation of $\mathrm{Ni}$ incorporated into the calcite lattice. These differences likely reflect a larger $\mathrm{Ni}-\mathrm{O}$ bond length of $\mathrm{Ni}$ incorporated in the crystal lattice compared to that present in $\mathrm{Ni}$ complexes on the calcite surface. Note that $\mathrm{Ni}$ adsorbed on calcite at the onset of co-precipitation experiments accounts for only a negligible fraction of the total $\mathrm{Ni}$ incorporated in calcite. Using a value of the $\mathrm{Ni}$ partition coefficient during $\mathrm{Ni}$ adsorption on calcite, $\mathrm{Kd}=0.011$ at $\mathrm{pH} 8.3$ (Castillo Alvarez et al., 2020) it is found that the mass of $\mathrm{Ni}$ adsorbed on calcite surfaces at the onset of a co-precipitation experiment never exceeded $7.8 \times 10^{-8} \mathrm{~g}$ (note the value of $\mathrm{Kd}$ at the 6.0-

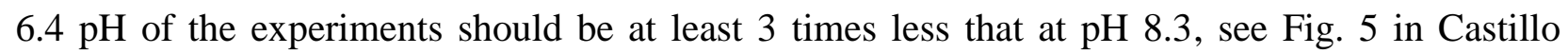
Alvarez et al., 2020). In comparison the mass of $\mathrm{Ni}$ incorporated in calcite during the coprecipitation experiments of this study ranged between $5.2 \times 10^{-4}$ and $1 \times 10^{-3} \mathrm{~g}$, thus about 4 orders of magnitude higher. As a result the $\mathrm{Ni}$ isotope composition of $\mathrm{Ni}$ co-precipitated with calcite will not be affected by $\mathrm{Ni}$ sorbed on calcite at the onset of co-precipitation experiments. 
Aqueous $\mathrm{Ni}$ complexation with the ligands present in our experimental solution was 613 insufficient to significantly impact $\mathrm{Ni}^{2+}(\mathrm{aq})$ isotope composition and calcite $\mathrm{Ni}$ isotope 614 composition. At the conditions of our experiments $\left(\mathrm{pH} \leq 6.4\right.$, Alk. $\left.\leq 0.037 \mathrm{~N}, \mathrm{Cl}^{-}=0.2 \mathrm{~N}\right)$, $615 \mathrm{NiHCO}_{3}{ }^{+}$was the only significant $\mathrm{Ni}$ aqueous complex present in solution, with a fraction of total 616 dissolved $\mathrm{Ni}$ that never exceeded $11.3 \%$, and $\mathrm{Ni}^{2+}(\mathrm{aq})$ accounted for at least $88 \%$ of dissolved 617 nickel. Using the values of the reduced partition functions for the ${ }^{60} \mathrm{Ni} /{ }^{58} \mathrm{Ni}$ isotope pairs of $618 \mathrm{Ni}^{2+}$ (aq) and $\mathrm{NiHCO}_{3}{ }^{+}$reported by Fujii et al. (2011), it can be concluded that $\mathrm{Ni}-\mathrm{HCO}_{3}{ }^{-}$ 619 complexation led to an enrichment of $\mathrm{Ni}^{2+}(\mathrm{aq})$ in ${ }^{58} \mathrm{Ni}$ of no more than $0.05 \%$, a value less than 620 the uncertainty attached to our measurements.

Why does the magnitude of Ni isotope fractionation decreases with increasing calcite growth rate?

When minerals precipitate from aqueous fluids at high growth rates the system is not likely at isotopic equilibrium. Such non-equilibrium effects have been reported in a number of systems (Lemarchand et al. 2004; Fantle and DePaolo 2007; Tang et al. 2008; Böhm et al. 2012; Mavromatis et al. 2013). Ions in aqueous solution need to dehydrate before they can be incorporated into the calcite crystal lattice (e.g. Marriott et al., 2004; Raiteri and Gale, 2010) and water molecules have shorter residence times in the solvation shells around lighter isotopes (Hofmann et al. 2012). For metals like $\mathrm{Ca}$ and $\mathrm{Sr}$, the ion desolvation rate has been suggested to 631 be the primary mechanism responsible for the enrichment of light metal isotopes in the calcite 632 crystal (Hofmann et al. 2012). Indeed, Lammers et al. (2020) showed, based on molecular 633 simulations that the preferential dehydration of light $\mathrm{Ca}$ isotopes at the calcite surface only occurs 634 at kink sites during classical spiral growth. This should lead to the preferential attachment of light metal isotopes to advancing steps on calcite surfaces and to an increasing extent of fractionation with increasing growth rates, such as seem in Fig. 7. Also shown in this figure are the measured isotopic fractionation between calcite and aqueous fluids for $\mathrm{Ni}, \mathrm{Mg}$, and $\mathrm{Sr}$ as a function of the 638 calcite growth rate. The behavior for $\mathrm{Ni}$ is similar to that observed for $\mathrm{Mg}$, but contrasts to that 639 observed for $\mathrm{Ca}, \mathrm{Sr}$ and $\mathrm{Ba}$ in calcite (Böhm et al. 2012; Mavromatis et al. 2013, 2020; AlKhatib 640 and Eisenhauer 2017). 


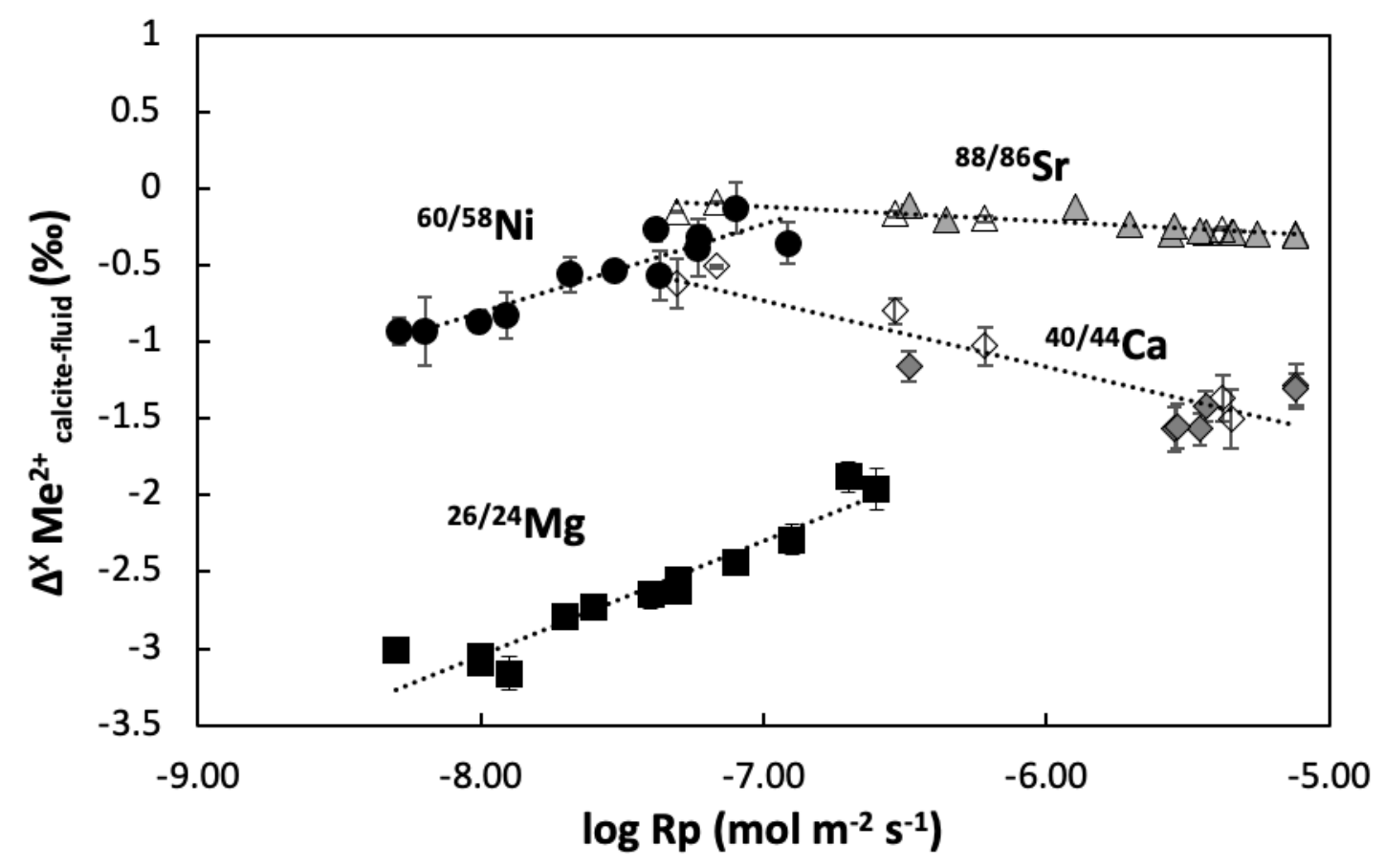

Figure 7 Isotope fractionation factor between calcite and aqueous fluids for $\mathrm{Ni}, \mathrm{Mg}, \mathrm{Sr}$, and Ca plotted as a function of the logarithm of the calcite growth rate log $R_{p}$. The data plotted for $\mathrm{Mg}, \mathrm{Sr}$, and Ca was originally reported by Mavromatis et. al. (2013, black squares), AlKhatib and Eisenhauer (2017, triangles), and Bohm et. al. (2012, diamonds).

These observations are consistent with the relative rate of $\mathrm{H}_{2} \mathrm{O}$ exchange in the aqueous metal coordination sphere compared to that of Ca. Strontium, barium and calcium have similar water exchange rates $\left(10^{-8.9}, 10^{-9.2}\right.$ and $10^{-8.8} \mathrm{~s}^{-1}$, respectively) and exhibit similar isotope fractionation trends. In contrast $\mathrm{Ni}$ and $\mathrm{Mg}$ have water exchange rates of $10^{-4.3}$ and $10^{-5.4} \mathrm{~s}^{-1}$ respectively, and show the opposite isotope fractionation trend as a function of calcite growth rate. $\mathrm{As}_{\mathrm{Ca}^{2+}}$ desolvation is the rate limiting step for calcite growth, it is unlikely that $\mathrm{Ni}$, which desolvates at rates 5 orders of magnitude slower than $\mathrm{Ca}$, completely desolvates as it incorporates into the calcite structure except at very slow calcite growth rates (Watkins et al., 2017). As a result there is, at rapid calcite growth rates, less isotope fractionation between calcite and the $\mathrm{Ni}$ aquo ion. It has been shown that the high hydration energy of aqueous metals like $\mathrm{Ni}^{2+}(\mathrm{aq})$ slows

658 their dehydration on the calcite surface and within its surface layer (Mavromatis et al., 2013).

659 Nickel attached to the calcite surface remains partly hydrated even after its incorporation into the 660 calcite structure, as suggested by the value of $\mathrm{Ni}$ partition coefficient measured in this study (see 661 above). This relatively slow desolvation rate relative to $\mathrm{Ca}^{2+}$ results in a kinetic isotope 662 fractionation involving dehydration of ions, which prevails over the preferential attachment of light $\mathrm{Ni}$ isotopes to kink sites during the classical growth mechanism operating in our experiments 
665

666

667

668

669

670

671

672

673

674

675

676

677

678

679

680

681

682

683

684

685

686

687

688

689

690

691

692

693

694

695

696

697

\section{.}

Can Ni isotopes in calcite track past seawater Ni isotopic compositions?

The deviations of $\mathrm{Ni}$ isotope fractionations from equilibrium fractionation can be used to gather information on geochemical processes and paleoenvironments. Given the correlation that exists between the isotope fractionation of $\mathrm{Ni}$ and the calcite growth rate, $\mathrm{Ni}$ isotopic compositions of primary calcite have the potential to record information of the seawater composition at the time of deposition. Notably, the use of $\mathrm{Ni}$ isotope compositions to determine the growth rates and thereby the saturation state of calcite during its time of formation can provide an independent test for paleoenviromental reconstructions when used together with other marine calcite proxies. It should be pointed out that $\mathrm{Ni}^{2+}$ complexation with the main dissolved inorganic ligands of modern seawater $\left(\mathrm{SO}_{4}{ }^{2-}, \mathrm{CO}_{3}{ }^{2-}, \mathrm{HCO}_{3}{ }^{-}, \mathrm{Cl}^{-}\right)$should not significantly impact the isotopic composition of the $\mathrm{Ni}^{2+}$ incorporated in calcite lattice. Indeed, at $\mathrm{pH} \mathrm{8.2,} \mathrm{dissolved}$ nickel is predominately in the form of the $\mathrm{Ni}^{2+}$ aquo ion $(\sim 77 \%)$ and the formation of $\mathrm{NiSO}_{4}{ }^{\circ}$ $(19.1 \%), \mathrm{NiCO}_{3}{ }^{\circ}(2.1 \%), \mathrm{NiHCO}_{3}{ }^{+}(0.4 \%)$ and $\mathrm{NiCl}^{+}(0.2 \%)$ leads, according to the reduced partition functions for the isotope pairs of aqueous Ni species reported by Fujii et al. (2011), to an enrichment of $\mathrm{Ni}^{2+}(\mathrm{aq})$ of only $0.1 \%$ in ${ }^{58} \mathrm{Ni}$.

\subsection{Resolving the Ni isotope imbalance in the ocean}

A number of previous studies concluded that our current understanding of the Ni isotopic balance in the oceans is not well constrained. The nickel isotope composition of seawater has been reported to be between $\delta^{60} \mathrm{Ni}=1.20$ and $1.74 \%$ (Cameron and Vance 2014; Takano et al. 2017; Archer et al. 2020) while rivers, the main input of Ni into the ocean, are substantially lighter with an annual $\delta^{60} \mathrm{Ni}$ average of $+0.80 \%$ (Cameron and Vance 2014). This difference in the isotopic composition of the ocean compared to rivers requires the existence of either another source of isotopically heavy $\mathrm{Ni}$ or an additional sink of isotopically light $\mathrm{Ni}$.

Various processes have been suggested as the possible light Ni sink from the oceans including the adsorption of $\mathrm{Ni}$ on $\mathrm{Fe}-\mathrm{Mn}$ oxides, the incorporation of $\mathrm{Ni}$ into sulfide-rich sediments, Ni uptake into organic matter and biological uptake (Gall et al. 2013; Gueguen et al. 2013; Wasylenki et al. 2015; Vance et al. 2016, 2017; Ciscato et al. 2018; Archer et al. 2020; Little et al., 2020), yet ambiguities remain (Cameron and Vance 2014; Ciscato et al. 2018). Castillo Alvarez et al. (2020) showed that light Ni isotopes are preferentially adsorbed onto calcite with a $\Delta^{60} \mathrm{Ni}_{\text {calcite-fluid }}=-0.49 \pm 0.16 \%$. The present study demonstrates that light $\mathrm{Ni}$ is also 
698 preferentially co-precipitated with calcite with $\Delta^{60} \mathrm{Ni}_{\text {calcite-fluid }}$ of $-1.0 \%$ or larger. These results

699 suggest that $\mathrm{Ni}$ adsorption onto calcite surfaces and $\mathrm{Ni}$ coprecipitation into calcite may contribute 700 to resolving the imbalance in the global marine $\mathrm{Ni}$ budget given the large mass of calcite 701 precipitated in the oceans.

702

703

704

705

706

707

708

709

710

711

712

713

714

715

716

717

718

719

720

721

722

723

724

725

726

727

728

The quantification of the amount of $\mathrm{Ni}$ in marine carbonates and its isotopic composition is necessary to accurately estimate the contribution of $\mathrm{Ni}$ uptake in calcite to the $\mathrm{Ni}$ marine isotope budget. The annual output flux of $\mathrm{Ni}$ from the oceans via carbonate precipitation is challenging to constrain and current estimates have substantial uncertainties. Ciscato et al. (2018) suggested that the $\mathrm{Ni}$ buried with $\mathrm{CaCO}_{3}$ accounts for only about 1 to $2 \%$ of the total $\mathrm{Ni}$ sink from the oceans. This estimate does not, however, account for carbonates precipitated in a number of environments such as deltaic sediments, representing roughly $45 \%$ of the carbonates buried, and that buried along the continental shelves and slopes (Hedges and Keil 1995). An alternate estimate could be made by recalling that the removal of $\mathrm{CaCO}_{3}$ from seawater has been estimated to be between 3.2 and $14.7 \times 10^{13} \mathrm{~mol}$ of carbonate per year (Hedges and Keil, 1995; Milliman and Droxler, 1996; Milliman et al., 1999; Schneider et al., 2000; Berelson et al., 2007). This $\mathrm{CaCO}_{3}$ contains between 1.52 and $12.92 \mathrm{ppm}$ of $\mathrm{Ni}$ (Zhao and Zheng 2014) with an average of $2.69 \mathrm{ppm}$ of Ni. Multiplying the annual mass of $\mathrm{CaCO}_{3}$ removed from seawater by this average $\mathrm{Ni}$ concentration would results in the removal of 1.5 to $6.7 \times 10^{8}$ moles of Ni by carbonate minerals each year. This compares to an estimated global riverine input of $\mathrm{Ni}$ to the oceans of $3.6 \times 10^{8} \mathrm{~mol} / \mathrm{year}$ (Cameron and Vance, 2014) and an estimated flux of Ni from the oceans of 7.2 to $17 \times 10^{8} \mathrm{~mol} / \mathrm{year}$. It has been argued, however, that these latter estimates present a mass balance problem as they are 2-5 times the quantified input (Ciscato et al., 2018). The mass of Ni estimated here to be removed from the ocean via carbonate precipitation ranges from 40 to $180 \%$ of that estimated to be added to oceans by global rivers. Although such estimates are highly uncertain, the observation that the measured Ni fractionation into calcite during its coprecipitation ranges up to at least $-1.0 \%$, the removal of $\mathrm{Ni}$ by its incorporation into $\mathrm{CaCO}_{3}$ exported from the ocean could change notably the $\mathrm{Ni}$ isotope composition of seawater. As such this process could help to bridge the gap between the $\mathrm{Ni}$ isotope composition of sources and sinks in the ocean.

\section{CONCLUSIONS}


Experiments were performed to determine the effect of the calcite growth rate on the degree of $\mathrm{Ni}$ isotope fractionation during its coprecipitation at $25^{\circ} \mathrm{C}$, a $\mathrm{pH}$ of 6.2 , and a $\mathrm{pCO}_{2}$ of 1 atm. The major results of this study include:

1) Lighter $\mathrm{Ni}$ isotopes were preferentially incorporated into precipitated calcite. This is likely the result of the change in Ni coordination environment occurring during the incorporation process. Nickel does not change its coordination number as it incorporates into calcite from aqueous fluids. The Ni-O interatomic distance, however, is significantly longer for $\mathrm{Ni}$ incorporated in calcite than it is for aqueous $\mathrm{Ni}\left(\mathrm{H}_{2} \mathrm{O}\right)_{6}{ }^{2+}$. The value of $\mathrm{Ni}$ equilibrium fractionation, $\Delta^{60} \mathrm{Ni}_{\text {calcite-fluid }}$, derived in this study is $\leq-1.0 \%$. This is more negative than the corresponding value for $\mathrm{Ni}$ sorption on calcite surface $(-0.49 \%$ o). This difference likely reflects longer $\mathrm{Ni}-\mathrm{O}$ bond lengths for the $\mathrm{Ni}$ incorporated into calcite than for the $\mathrm{Ni}$ species adsorbed at the calcite surface.

2) Nickel isotope fractionation between calcite and fluid depends on the calcite growth rate. The measured nickel isotope fractionation changes from -0.9 to $-0.2 \%$ as the calcite growth rate increases from $10^{-8.3}$ to $10^{-6.9} \mathrm{~mol} \mathrm{~m}^{-2} \mathrm{~s}^{-1}$. The decrease in the extent of $\mathrm{Ni}$ isotope fractionation as the growth rate increases is attributed to the slow dehydration rate of aqueous $\mathrm{Ni}^{2+}$. This slow dehydration hinders the incorporation of dehydrated $\mathrm{Ni}^{2+}$ into calcite, a behavior similar to that observed for $\mathrm{Mg}$, but contrasts to the behavior exhibited by $\mathrm{Ca}, \mathrm{Sr}$ and $\mathrm{Ba}$. These observations likely stem from the rate of exchange of $\mathrm{H}_{2} \mathrm{O}$ of the aqueous metals in their coordination sphere compared to that of aqueous $\mathrm{Ca}^{2+}$.

3) The precipitation rate of marine carbonates is determined by the saturation state of the ocean with respect to these minerals. At the same time, the saturation state of carbonates is influenced by $\mathrm{pH}, \mathrm{pCO}_{2}$ and temperature. As $\mathrm{Ni}$ isotope fractionation in calcite depends on its growth rate, measured $\mathrm{Ni}$ isotope compositions have the potential to reveal information on past environmental conditions.

4) The preferred enrichment in light $\mathrm{Ni}$ isotopes on/in calcite from seawater during adsorption and precipitation likely contributes to solving the $\mathrm{Ni}$ isotope budget imbalance in the ocean given the large amount of $\mathrm{Ni}$ that gets incorporated into carbonate minerals

\section{ACKNOWLEDGEMENTS}

The research was supported by ISONOSE a People Programme (Marie Curie Actions) of 
agreement $\mathrm{n}^{\circ}$ [608069]. We thank Alain Castillo for BET measurements, Carole Causserand from the Géosciences Environement Toulouse for their assistance in the laboratories. We would also like to thank Christian Benker, Vassilis Mavromatis, and Martin Voigt for helpful discussions.

\section{REFERENCES}

AlKhatib M. and Eisenhauer A. (2017) Calcium and strontium isotope fractionation in aqueous solutions as a function of temperature and reaction rate; I. Calcite. Geochim. Cosmochim. Acta 209, 296-319.

Archer C, Vance D, Milne A, and Lohan MC (2020) The oceanic biogeochemistry of nickel and its isotopes: New data from the South Atlantic and the Southern Ocean biogeochemical divide. Earth Planet Sci Lett 535:116118. doi: 10.1016/j.epsl.2020.116118

Böhm F., Eisenhauer A., Tang J., Dietzel M., Krabbenhöft A., Kisakürek B. and Horn C. (2012) Strontium isotope fractionation of planktic foraminifera and inorganic calcite. Geochim. Cosmochim. Acta 93, 300-314.

Berelson. W.M., Balch, W.M., Najjar, R., Feely, R.A., Sabine, C. and Lee, K. (2007) Relating estimates of $\mathrm{CaCO}_{3}$ production, export, and dissolution in the water column to measurements of $\mathrm{CaCO}_{3}$ rain into sediment traps ad dissolution on the seafloor. Global Biogeo. Cycles, 21, GB002803.

Brunauer S., Emmett P. H. and Teller E. (1938) Adsorption of Gases in Multimolecular Layers. J. Am. Chem. Soc. 60, 309-319.

Cameron V. and Vance D. (2014) Heavy nickel isotope compositions in rivers and the oceans. Geochim. Cosmochim. Acta 128, 195-211.

Caminiti R., Licheri G., Piccaluga G. and Pinna G. (1977) X-ray diffraction and structure of $\mathrm{NiCl}_{2}$ aqueous solutions. Faraday Discuss. Chem. Soc. 64, 62.

Carlsson, T., and Aalto, H. (1997). Coprecipitation of Ni with calcite: An experimental study. MRS Proceedings, 506, 621. doi:10.1557/PROC-506-621

Castillo Alvarez C., Quitté G., Schott J. and Oelkers E. H. (2020) Experimental determination of Ni isotope fractionation during $\mathrm{Ni}$ adsorption from an aqueous fluid onto calcite surfaces. Geochim. Cosmochim. Acta 273, 26-36.

Ciscato, E.R., Bontognali, T.R.R. and Vance, D. (2018) Nickel and its isotopes in organic-rich sediments: Implications for oceanic budgets and a potential record of ancient seawater. Earth Planet. Sci. Lett. 494, 239-250.

Criss R. E. (1999) Principles of stable isotope distribution, Oxford University Press.

Curti E. (1999) Coprecipitation of radionuclides with calcite: Estimation of partition coefficients based on a review of laboratory investigations and geochemical data. Appl. Geochemistry $14,433-445$. 
Dickson A. G. and Goyet C. (1994) Handbook of methods for the analysis of the various parameters of the carbon dioxide system in sea water. Version 2. Epic. Diego, ORNL/CDIAC-74.

Dromgoole E. L. and Walter L. M. (1990) Iron and manganese incorporation into calcite: Effects of growth kinetics, temperature and solution chemistry. Chem. Geol. 81, 311-336.

Fantle M. S. and DePaolo D. J. (2007) Ca isotopes in carbonate sediment and pore fluid from ODP Site 807A: The $\mathrm{Ca}^{2+}(\mathrm{aq})$-calcite equilibrium fractionation factor and calcite recrystallization rates in Pleistocene sediments. Geochim. Cosmochim. Acta 71, 2524-2546.

Elzinga, E.J., Reeder, R.J., Withers, S.H., Peale, R.E., Mason, R.A., Beck, K.M., and Hess, W.P; (2002) EXAFS study of rare-earth element coordination in calcite. Geochim. Cosmochim. Acta 66, 2875-2885.

Fujii T., Moynier F., Dauphas N. and Abe M. (2011) Theoretical and experimental investigation of nickel isotopic fractionation in species relevant to modern and ancient oceans. Geochim. Cosmochim. Acta 75, 469-482.

Gall L., Williams H. M., Siebert C., Halliday A. N., Herrington R. J. and Hein J. R. (2013) Nickel isotopic compositions of ferromanganese crusts and the constancy of deep ocean inputs and continental weathering effects over the Cenozoic. Earth Planet. Sci. Lett. 375, 148-155.

Gamsjäger, H., Preis, W., and Wallner, H. Solute-solute phase equilibria in aqueous solutions. XIV. Thermodynamics analysis of the solubility of hallyerite in water. Monats. Chimie 132, 411415.

Gueguen B., Rouxel O., Ponzevera E., Bekker A. and Fouquet Y. (2013) Nickel Isotope Variations in Terrestrial Silicate Rocks and Geological Reference Materials Measured by MC-ICP-MS. Geostand. Geoanalytical Res. 37, 297-317.

Hedges, J.I. and Keil, R.G. (1995) Sedimentary organic matter preservation: An assessment and speculative synthesis. Mar. Chem., 49, 81-115

Henderson L. M. and Kracek F. C. (1927) The fractional precipitation of barium and radium chromates 1. J. Am. Chem. Soc. 49, 738-749.

Hofmann A. E., Bourg I. C. and DePaolo D. J. (2012) Ion desolvation as a mechanism for kinetic isotope fractionation in aqueous systems. Proc. Natl. Acad. Sci. 109, 18689-18694.

Kitano Y., Okumura M. and Idogaki M. (1980) Abnormal behaviors of copper (II) and zinc ions in parent solution at the early stage of calcite formation. Geochem. J. 14, 167-175.

Lafuente B., Downs R. T., Yang H. and Stone N. (2016) The power of databases: The RRUFF project. In Highlights in Mineralogical Crystallography pp. 1-29.

Lakshtanov L. Z. and Stipp S. L. S. (2007) Experimental study of nickel(II) interaction with calcite: Adsorption and coprecipitation. Geochim. Cosmochim. Acta 71, 3686-3697.

Lammers LN, Kulasinski K, Zarzycki P, and DePaolo DJ (2020) Molecular simulations of kinetic stable calcium isotope fractionation at the calcite-aqueous interface. Chem Geol 532:119315. doi: 10.1016/j.chemgeo.2019.119315 
Lemarchand D., Wasserburg G. J. and Papanastassiou D. A. (2004) Rate-controlled calcium isotope fractionation in synthetic calcite. Geochim. Cosmochim. Acta 68, 4665-4678.

Little S.H., Archer C., McManus J., N.ajorka J., Wegorzewski, A.V. and Vance, D. (2020) Towards balancing the oceanic Ni budget. Earth Planet. Sci. Let. 547, 116461.

Lorens R. B. (1981) Sr, Cd, Mn and Co distribution coefficients in calcite as a function of calcite precipitation rate. Geochim. Cosmochim. Acta 45, 553-561.

Magini M., Paschina G. and Piccaluga G. (1982) Ni-Cl bonding in concentrated Ni(II) aqueous solutions at high $\mathrm{Cl}^{-} / \mathrm{Ni}^{2+}$ ratios. An $\mathrm{x}$ - ray diffraction investigation. J. Chem. Phys. 76, 1116-1121.

Marchitto T. M. (2011) Zinc and cadmium in benthic foraminifera as tracers of ocean paleochemistry. Ph.D. Thesis, Massachusetts Institute of Technology, 203 p.

Marques Fernandes, M., Schmidt, M., Stumpf, T., Walther, C., Bosbach, D., Klenze, R., and Fanghänel Th. (2008) Site-selective-time-resolved laser fluorescence spectroscopy of $\mathrm{Eu}^{3+}$ in calcite. J. Colloid Interface Sci. 321, 323-331.

Marriott C. S., Henderson G. M., Belshaw N. S. and Tudhope A. W. (2004) Temperature dependence of $\delta^{7} \mathrm{Li}, \delta^{44} \mathrm{Ca}$ and $\mathrm{Li} / \mathrm{Ca}$ during growth of calcium carbonate. Earth Planet. Sci. Lett. 222, 615-624.

Mavromatis V., Gautier Q., Bosc O. and Schott J. (2013) Kinetics of Mg partition and Mg stable isotope fractionation during its incorporation in calcite. Geochim. Cosmochim. Acta 114, 188-203.

Mavromatis V., González A. G. A. G., Dietzel M. and Schott J. (2019) Zinc isotope fractionation during the inorganic precipitation of calcite - Towards a new $\mathrm{pH}$ proxy. Geochim. Cosmochim. Acta 244, 99-112.

Mavromatis, V., van Zuilen, K., Blanchard, M., van Zuilen, M., Dietzel M., and Schott, J. (2020) Experimental and theoretical modeling of kinetic and equilibrium Ba isotope fractionation during calcite and aragonite precipitation. Geochim. Cosmochim. Acta 269, 566-580.

Milliman J. D. and Droxler A. W. (1996) Neritic and pelagic carbonate sedimentation in the marine environment: ignorance is not bliss. Geol. Rundschau 85, 496-504.

Milliman J. D., Troy P. J., Balch W. M., Adams A. K., Li Y.-H. and Mackenzie F. T. (1999) Biologically mediated dissolution of calcium carbonate above the chemical lysocline? Deep Sea Res. Part I Oceanogr. Res. Pap. 46, 1653-1669.

Mucci A. and Morse J. W. (1983) The incorporation of $\mathrm{Mg}^{2+}$ and $\mathrm{Sr}^{2+}$ into calcite overgrowths: Influences of growth rate and solution composition. Geochim. Cosmochim. Acta 47, 217233.

Munsel D., Kramar U., Dissard D., Nehrke G., Berner Z., Bijma J., Reichart G. J. and Neumann T. (2010) Heavy metal incorporation in foraminiferal calcite: Results from multi-element enrichment culture experiments with Ammonia tepida. Biogeosciences 7, 2339-2350. 
Parkhurst D.L. and Appelo C.A.J. (2013) Description of input and examples for PHREEQC version 3: a computer program for speciation, batch-reaction, one-dimensional transport, and inverse geochemical calculations. US Geological Survey Techniques and Methods, book 6, chap. A43, U.S. Geological Survey, p. 497.

Pertlik F. (1986) Structures of hydrothermally synthesized cobalt(II) carbonate and nickel(II) carbonate. Acta Cryst. 42, 4-5.

Pingitore N. E. and Eastman M. P. (1984) The experimental partitioning of $\mathrm{Ba}^{2+}$ into calcite. Chem. Geol. 45, 113-120.

Quitté G. and Oberli F. (2006) Quantitative extraction and high precision isotope measurements of nickel by MC-ICPMS. J. Anal. At. Spectrom. 21, 1249-1255.

Raiteri P. and Gale J. D. (2010) Water is the key to nonclassical nucleation of amorphous calcium carbonate. J. Am. Chem. Soc. 132, 17623-17634.

Reeder R. J. (1990) Crystal chemistry of the rhombohedral carbonates. Rev. Miner. 11, 1-47.

Reeder R. J., Lamble G. M. and Northrup P. A. (1999) XAFS study of the coordination and local relaxation around $\mathrm{Co}^{2+}, \mathrm{Zn}^{2+}, \mathrm{Pb}^{2+}$, and $\mathrm{Ba}^{2+}$ trace elements in calcite. Am. Miner. 84, 10491060.

Rimstidt J. D., Balog A. and Webb J. (1998) Distribution of trace elements between carbonate minerals and aqueous solutions. Geochim. Cosmochim. Acta 62, 1851-1863.

Rodler A., Sánchez-Pastor N., Fernández-Díaz L. and Frei R. (2015) Fractionation behavior of chromium isotopes during coprecipitation with calcium carbonate: Implications for their use as paleoclimatic proxy. Geochim. Cosmochim. Acta 164, 221-235.

Sandstrom D. R. (1979) $\mathrm{Ni}^{2+}$ coordination in aqueous $\mathrm{NiCl}_{2}$ solutions: Study of the extended $\mathrm{x}$-ray absorption fine structure. J. Chem. Phys. 71, 2381-2386.

Saulnier S., Rollion-Bard C., Vigier N. and Chaussidon M. (2012) Mg isotope fractionation during calcite precipitation: An experimental study. Geochim. Cosmochim. Acta 91, 75-91.

Schauble, E.A., 2004. Applying Stable Isotope Fractionation Theory to New Systems. Rev. Mineral. Geochem. 55, 65-111.

Schneider R.R., Schulz H.D., and Hensen C. (2000) Marine Carbonates: Their Formation and Destruction. In: Schulz H.D., Zabel M. (eds) Marine Geochemistry. Springer, Berlin, Heidelberg, p. 283-307.

Schott J., Mavromatis V., González-González A., Oelkers E. H. (2014) Kinetic and thermodynamic controls of divalent metals isotope composition in carbonate: Experimental investigations and applications. Procedia Earth Planet. Sci. 10, 168-172.

Sohrin Y. and Bruland K. W. (2011) Global status of trace elements in the ocean. TrAC Trends Anal. Chem. 30, 1291-1307.

Stumm W M. J. (1996) Aquatic Chemistry: Chemical Equilibria and Rates in Natural Waters., Wiley, New York. 
Takano S., Tanimizu M., Hirata T., Shin K.-C., Fukami Y., Suzuki K. and Sohrin Y. (2017) A simple and rapid method for isotopic analysis of nickel, copper, and zinc in seawater using chelating extraction and anion exchange. Anal. Chim. Acta 967, 1-11.

Tang J., Köhler S. J. and Dietzel M. (2008) $\mathrm{Sr}^{2+} / \mathrm{Ca}^{2+}$ and ${ }^{44} \mathrm{Ca} /{ }^{40} \mathrm{Ca}$ fractionation during inorganic calcite formation: I. Sr incorporation. Geochim. Cosmochim. Acta 72, 3718-3732

Tesoriero A. J. and Pankow J. F. (1996) Solid solution partitioning of $\mathrm{Sr}^{2+}, \mathrm{Ba}^{2+}$, and $\mathrm{Cd}^{2+}$ to calcite. Geochim. Cosmochim. Acta 60, 1053-1063.

Vance D., Archer C., Little S. H., Köbberich M. and de Souza G. F. (2017) The oceanic cycles of the transition metals and their isotopes. Acta Geochim. 36, 359-362.

Vance D., Little S. H., Archer C., Cameron V., Andersen M. B., Rijkenberg M. J. A. and Lyons T. W. (2016) The oceanic budgets of nickel and zinc isotopes: The importance of sulfidic environments as illustrated by the Black Sea. Phil.Trans.R.Soc.A 374.

Varadwaj P. R., Cukrowski I. and Marques H. M. (2008) DFT-UX3LYP Studies on the coordination chemistry of $\mathrm{Ni}^{2+}$. Part 1: Six Coordinate $\left[\mathrm{Ni}\left(\mathrm{NH}{ }_{3}\right) \mathrm{n}\left(\mathrm{H}_{2} \mathrm{O}\right) 6-\mathrm{n}^{2+}\right.$ complexes. J. Phys. Chem. A. 12, 10657-10666.

Voigt M., Mavromatis V. and Oelkers E. H. (2017) The experimental determination of REE partition coefficients in the water-calcite system. Chem. Geol. 462, 30-43.

von Allmen K., Böttcher M. E., Samankassou E. and Nägler T. F. (2010) Barium isotope fractionation in the global barium cycle: First evidence from barium minerals and precipitation experiments. Chem. Geol. 277, 70-77.

Wang Y. and Xu H. (2001) Prediction of trace metal partitioning between minerals and aqueous solutions: a linear free energy correlation approach. Geochim. Cosmochim. Acta 65, 15291543.

Wasylenki L. E., Howe H. D., Spivak-Birndorf L. J. and Bish D. L. (2015) Ni isotope fractionation during sorption to ferrihydrite: Implications for $\mathrm{Ni}$ in banded iron formations. Chem. Geol. 400, 56-64.

Watkins J. M., DePaolo D. J. and Watson E. B. (2017) Kinetic fractionation of non-traditional stable isotopes by diffusion and crystal growth reactions. Rev. Mineral. Geochem. 82, 85 125.

Watson E. B. (2004) A conceptual model for near-surface kinetic controls on the trace-element and stable isotope composition of abiogenic calcite crystals. Geochim. Cosmochim. Acta 68, $1473-1488$.

Webb G. E. and Kamber B. S. (2000) Rare earth elements in Holocene reefal microbialites: a new shallow seawater proxy. Geochim. Cosmochim. Acta 64, 1557-1565.

Zavarin M. and Doner H. (1999) Nickel and Manganese interaction with calcite. Lawrence Livermore National Laboratoty Report UCRL-ID-135402, doi:10.2172/12549

Zhao M.-Y. and Zheng Y.-F. (2014) Marine carbonate records of terrigenous input into Paleotethyan seawater: Geochemical constraints from Carboniferous limestones. Geochim. Cosmdochim. Acta 141, 508-531. 
958

959

960

961

962

963

964

965

966

967

968

969

970

971

972

973

974

975

976

977

978

979

980

981

Zhong S. and Mucci A. (1995) Partitioning of rare earth elements (REEs) between calcite and seawater solutions at $25^{\circ} \mathrm{C}$ and 1 atm, and high dissolved REE concentrations. Geochim. Cosmochim. Acta 59, 443-453.

APPENDIX

Thermodynamic description of nickel partition coefficient between the fluid and calcite

According to the thermodynamics of solid solutions (i.e. Saxena, 1973), Ni distribution coefficients, $\mathrm{D}_{\mathrm{Ni}}$, in the aqueous calcite-Ni carbonate system can be defined as the equilibrium constant of the exchange reaction given by

$$
\mathrm{CaCO}_{3}(\mathrm{ss})+\mathrm{Ni}^{2+}=\mathrm{NiCO}_{3}(\mathrm{ss})+\mathrm{Ca}^{2+},
$$

where $i(\mathrm{ss})$ stands for the ith component of the solid solution. The law of mass action for Eq. (A1) can be written

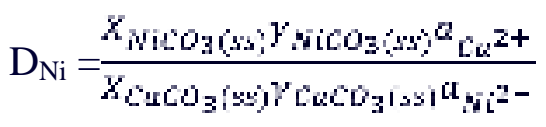

where $X_{i}$ and $\gamma_{i}$ represent the mole fraction and activity coefficient, respectively, of the ith component of the solid solution, and $a_{i}$ denotes the activity coefficient of the ith aqueous ion. For a dilute solid solution $\gamma_{L a t} v_{s}(s) \rightarrow 1$ and $\gamma_{\text {nico }} \rightarrow(r e) \rightarrow$ const. $\neq 1$. This leads to the classical expression of the apparent distribution coefficient, $\mathrm{D}_{\mathrm{Ni}}(\mathrm{ap})$, given by

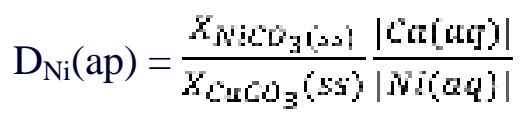

assuming no significant complexation of $\mathrm{Ni}(\mathrm{aq})$ and $\mathrm{Ca}(\mathrm{aq})$.

At equilibrium, the two constituents of the solid solution should be simultaneously in equilibrium with the two end-members of the solid solution, which provides two additional relations involving the calcite and $\mathrm{NiCO}_{3}$ solubility products:

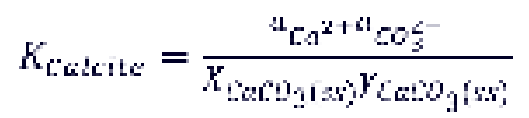

and

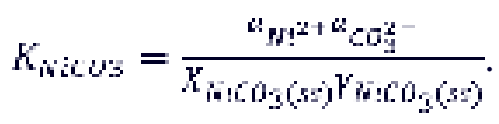


982 Combination of Eqs. A- 2, A-4 and A-5 provides the following expression for the partition 983 coefficient

$984 \quad \mathrm{D}_{\mathrm{Ni}}=\frac{\kappa_{\text {Caiatc }}}{i_{\text {iwicos }}}$

985 which allows determination of $\mathrm{D}_{\mathrm{Ni}}$ from the solubility products of the two end-members, calcite 986 and $\mathrm{NiCO}_{3}$. Based on the McIntire model (McIntire, 1963) and correlations of partition 987 coefficients for divalent metals that form rhombohedral carbonates, Rimstidt et al. (1998) 988 proposed the following expression similar to Eq. A-6:

989

$$
\mathrm{D}_{\mathrm{Ni}}=1.6\left(\frac{\kappa_{\text {Galatc }}}{\kappa_{\text {ini } 1 C \sigma_{\mathrm{y}}}}\right)^{3.37}
$$

990 Eqs A-6 and A-7 have been used in this study to calculate the values of $\mathrm{D}_{\mathrm{Ni}}$ considering two 991 different $\mathrm{Ni}$ carbonate end-members, the anhydrous $\mathrm{NiCO}_{3}$ (gaspeite) and $\mathrm{NiCO}_{3}\left(6 \mathrm{H}_{2} \mathrm{O}\right)$ 992 (hallyerite).

993

\section{References}

995 McIntire, W.L. (1963) Trace element partition coefficients - A review of theory and applications 996 to geology. Geochim. Cosmochim. Acta 27, 1209-1264.

997 Rimstidt J.D., Balog A., and Webb J. (1998) Distribution of trace elements between carbonate 998 minerals and aqueous solutions. Geochim. Cosmochim. Acta 62, 1851-1863.

999 Saxena S.K. (1973) The Thermodynamics of Rock-Forming Crystalline Solutions. SpringerVerlag, Berlin, 188 pp. 